\title{
MINAS SUBTERRÁNEAS: ¿VIDAS ASEGURADAS?
}

\author{
LAS MINAS DE CARBÓN Y LOS “POCITOS”. EL PROCEDIMIENTO \\ ADMINISTRATIVO DE INSPECCIÓN PERIÓDICA DE CONDICIONES \\ GENERALES DE SEGURIDAD E HIGIENE. EL CASO PARTICULAR DE MÉXICO
}

\author{
Dra. Susana Thalía Pedroza de la LlaVE* \\ Universidad Nacional Autónoma de México
}

\begin{abstract}
RESUMEN: Los estudios relacionados con las regiones mineras son escasos, por ello este trabajo ofrece una visión sobre el marco normativo que prevalece respecto a las minas de carbón y sobre las autoridades que participan en su regulación, concesión e inspección. Aborda la situación de las minas en México y en el contexto del derecho internacional, como por ejemplo, los hechos trágicos que han ocurrido. En este último ámbito se considera que poco se ha hecho en muchos países respecto de los problemas económicos, sociales y técnicos de la industria minera a pesar de que se han planteado en numerosas ocasiones medidas internacionales respecto a la explotación de minas, como lo es que la mayoría de los países deben ratificar el Convenio 176 de la OIT sobre seguridad y salud en las minas.
\end{abstract}

Palabras clave: El trabajo en las minas de carbón, las condiciones generales de seguridad e higiene en las minas, los derechos laborales de los mineros.

\begin{abstract}
Studies related to the mining regions are scarce, so this work provides insight into the regulatory framework that prevails over the coal mines and the authorities involved in its regulation, provision and inspection. Addresses the situation of the mines in Mexico and in the context of international law, such as the tragic events that have occurred. In the latter considered that little has been done in many countries for economic, social and technical aspects of the mining industry even though they have been raised on numerous occasions to international action on mining, such as that most countries must ratify the ILO Convention 176 on safety and health in mines.
\end{abstract}

Key words: Working in coal mines, the general conditions of hygiene and safety in mines, the labor rights of miners.

\section{CONSIDERACIÓN INTRODUCTORIA}

Este trabajo pretende, debido a que los estudios relacionados con las regiones mineras son escasos, proporcionar una visión sobre el marco normativo que prevalece hoy en día respecto a la regulación jurídica de las minas de carbón y sobre las autoridades que participan en su regulación, concesión e inspección. También aborda las diferencias que existen entre las minas y los llamados pocitos, su peligrosidad, así como los eventos trágicos que han ocurrido principalmente por negligencia existiendo una corresponsabilidad de todas las partes y violándose los derechos laborales entendidos como derechos humanos. Asimismo, se aborda el caso de las minas en México y en otros países, es decir, el contexto del derecho internacional. En este último ámbito, se considera que poco se ha hecho en muchos países respecto de

\footnotetext{
Doctora en Derecho por la Universidad Complutense de Madrid, España (1994); Diplomada en Derecho Constitucional y Ciencia Política por el Centro de Estudios Constitucionales de Madrid, España (1993); y Licenciada en Derecho por la Universidad Nacional Autónoma de México (UNAM) en 1991. Investigadora del Instituto de Investigaciones Jurídicas de la Universidad Nacional Autónoma de México. Agradezco el invaluable apoyo de Carolina Miranda Luévano para el desarrollo de este trabajo.
} 
los problemas económicos, sociales y técnicos de la industria minera a pesar de que se han planteado en numerosas ocasiones medidas internacionales respecto a la explotación de minas, como lo es que la mayoría de los países ratifiquen el Convenio 176 de la Organización Internacional del Trabajo (OIT) sobre seguridad y salud en las minas, que entró en vigor en 1998, y que fue adoptado el 22 de junio de 1995.

Por último, en este trabajo se analizarán cuáles son las necesidades en el sistema de justicia mexicano para fortalecer o hacer viable la operación de las minas bajo condiciones de seguridad e higiene, y se abordarán las conclusiones y propuestas para ver de qué manera se puede reformar esta materia y que se traduzca en beneficios para los mineros de nuestro país y de otros países.

\section{REGULACIÓN JURÍDICA DE LAS MINAS Y AUTORIDADES QUE PARTICIPAN EN SU REGULACIÓN Y CONCESIÓN}

En materia de minas de carbón, el artículo 27 de la Constitución Política de los Estados Unidos Mexicanos de 1917 vigente dispone que la propiedad de las tierras corresponde originariamente a la Nación, que tiene los derechos de transmitir su dominio a los particulares y de regular, en beneficio social, el aprovechamiento de los "elementos naturales susceptibles de apropiación", con objeto, entre otros, del "mejoramiento de las condiciones de vida de la población”. Para ello, se tendrán que dictar las medidas para el fomento de las actividades económicas y para evitar la destrucción de los elementos naturales y los daños que la propiedad pueda sufrir en perjuicio de la sociedad.

En este sentido, a la Nación le corresponde el dominio directo "de todos los recursos naturales, entre estos, los minerales". Son de su propiedad los que se extraigan de las minas pero, su explotación, uso o aprovechamiento por los particulares o sociedades no podrá realizarse, sino mediante concesiones otorgadas por el Ejecutivo Federal, de acuerdo con las reglas y condiciones que establezcan las Leyes, cuya inobservancia dará lugar a la cancelación de estas. A ese respecto, el artículo 73, fracción X, de la Constitución señala que el Congreso de la Unión tiene la facultad, entre otras, para legislar en toda la República sobre minería, y para expedir las leyes del trabajo reglamentarias del artículo 123.

Así, en cuanto al Congreso, tanto en la Cámara de Diputados ${ }^{1}$ como en la de Senadores $^{2}$ son varias las Comisiones ordinarias que están relacionadas con el tema que abordamos en este trabajo.

Ante estas Comisiones pueden acudir la ciudadanía, los sindicatos mineros, los empresarios, etcétera, y los integrantes de las mismas pueden realizar gestiones o dar orientación para la solución de un problema relativo a las minas de nuestro país. De igual forma, por disposición legal se pueden constituir Comisiones especiales como fue el caso de la creación de la

\footnotetext{
1 Derechos Humanos; Energía; Fomento Cooperativo y Economía Social; Función Pública; Gobernación; Jurisdiccional; Justicia; Medio Ambiente y Recursos Naturales; Puntos Constitucionales; Salud; Seguridad Social, y Trabajo y Previsión Social, cfr. http://sitl.diputados.gob.mx/listado_de_comisiones.php?tct=1 [consultada el 16 de junio de 2011].

2 Comercio y Fomento Industrial; Derechos Humanos; Energía; Fomento Económico; Gobernación; Jurisdiccional; Justicia; Medio Ambiente, Recursos Naturales y Pesca; Protección Civil; Puntos Constitucionales; Salud; Seguridad Social, y Trabajo y Previsión Social, cfr. http://www.senado.gob.mx/index.php?ver=int\&mn=41 [consultada el 16 de junio de 2011].
} 
Comisión Especial para conocer las responsabilidades y origen de la tragedia de la Mina Pasta de Conchos ${ }^{3}$, ocurrida en 2006, o, en otro caso, la creación de una Comisión especial para solucionar el conflicto laboral en la mina de cobre de Cananea, Sonora, en $2009^{4}$.

En este mismo ámbito del Congreso, en 2011, la Comisión de la Permanente citó a comparecer a los Secretarios del Trabajo; Economía; Energía; al titular de la CFE, y al Director General del Instituto Mexicano del Seguro Social (IMSS), para que rindieran un informe detallado precisamente sobre la situación de los trabajadores mineros en el país y, en particular, sobre la explosión en una mina de carbón, ubicada en Sabinas, Coahuila, que ocurrió el 3 de mayo de 2011, en la que murieron 14 personas y un menor de 15 años resultó lesionado con quemaduras graves y sufrió la pérdida de un brazo. En ese contexto varios diputados y senadores, integrantes de la Comisión Permanente, consideraron que en la región carbonífera de Coahuila es común y es una práctica que los concesionarios de los títulos de explotación minera celebren contratos con terceros, para que sean ellos los que se encarguen de la extracción del carbón, afirmando los parlamentarios que con dichos contratos se permite que los concesionarios reciban regalías por la explotación del carbón, pero sin responsabilizarse de cualquier irregularidad que se presente en la mina concesionada.

Otra problemática manifestada en el Congreso es la necesidad de presentar una iniciativa de reforma al artículo 123 constitucional para prohibir el trabajo de menores de edad en actividades riesgosas como la minería, ello después del accidente en Sabinas, Coahuila, donde se evidenció que menores de edad trabajaban en dicha mina ${ }^{5}$. Sin embargo, no es necesario reformar dicho artículo 123, sino que sería suficiente con reformar el numeral 175 de la Ley Federal del Trabajo.

Por otra parte, tratándose de minas, en el ámbito del derecho administrativo y con relación al derecho civil ${ }^{6}$, los términos para que se dé su exploración, explotación o beneficio depende del título que la Secretaría de Economía (SE) les otorgue, ya sea por asignación o por concesión minera ${ }^{7}$. En dicha Secretaría existe una Coordinación General de Minería, una Dirección General de Minas ${ }^{8}$, una Subdirección de Minas ${ }^{9}$, el Servicio Geológico Mexicano ${ }^{10}$ y, por último, existe una Dirección del Registro Público de Minería y Derechos Mineros ${ }^{11}$.

3 Cfr. http://www.diputados.gob.mx/servicios/datorele/LX_LEG/1\%20POS\%20II\%20ANO/04-oct-07/2.htm [consultada el 21 de junio de 2011].

4 Cfr. Gaceta Parlamentaria, número 2851-II, miércoles 23 de septiembre de 2009, en: http://gaceta.diputados.gob.mx/ Gaceta/Proposiciones/61/gp61_P_alprimero.html [consultada el 21 de junio de 2011].

5 Cfr. http://www.eluniversal.com.mx [consultada el 20 y 25 de mayo de 2011].

6 Para ampliar estos temas, consúltese García, Trinidad, "Registro de Concesiones y otros Actos, en Materia de Minas, Petróleo y Aguas", en: PEMEX Lex. Revista Jurídica de Petróleos Mexicanos, N 51-52, septiembre-octubre de 1992, pp. 54-55.

7 Cfr. http://www.pot.gob.mx/FastPOT2/search.jsp?collection=Fracciones\&10=numHits\&query=MINAS, [consultada el 29 de junio de 2011], en donde aparecen publicadas las más recientes concesiones.

8 Cfr. http://www.economia-dgm.gob.mx/Default.htm [consultada el 29 de junio de 2011].

9 Cfr. http://www.pot.gob.mx/FastPOT2/search.jsp?collection=Fracciones\&10=numHits\&query=MINAS [consultada el 29 de junio de 2011].

10 Cfr. http://www.sgm.gob.mx/index.php [consultada el 29 de junio de 2011].

11 Cfr. http://www.economia.gob.mx/swb/es/economia/p_cgm_A3_registropublicomineria [consultada el 29 de junio de 2011]. 
Cabe aclarar que en este trabajo se desarrollará preferentemente el tema de la concesión minera por ser esta la que le confiere derechos y obligaciones a las empresas carboníferas y ser en estas donde se han presentado el mayor número de casos de accidentes por diversos motivos que ya se desarrollarán.

En esta materia, la asignación minera se otorga únicamente a favor del Servicio Geológico Mexicano con el objeto de identificar y cuantificar los recursos minerales potenciales de la Nación. En cambio, las concesiones mineras son otorgadas para la exploración ${ }^{12}$ y explotación ${ }^{13}$ a personas físicas de nacionalidad mexicana, ejidos y comunidades agrarias, pueblos y comunidades indígenas, y personas jurídicas constituidas con apego a la legislación mexicana. Todos los anteriores deben contar con la capacidad para ser titulares de concesiones mineras, creándose un derecho respecto del bien que es su objeto, entrando en posesión del mismo ${ }^{14}$, además deberán referir su objeto social a la exploración o explotación de los minerales o sustancias sujetas a la aplicación de la Ley Minera ${ }^{15}$ (en este caso al carbón mineral en todas sus variedades y al gas asociado a los yacimientos de este) ${ }^{16}$, tener su domicilio legal en la República Mexicana y, en el caso de que cuenten con participación extranjera, estas inversiones deberán ajustarse a las disposiciones de la ley de la materia.

Para que se pueda otorgar una concesión minera, primero, se habrá de considerar que la zona a constituir como lote minero no forme parte de una reserva minera; lo cual

12 La exploración tiene por objeto la identificación de depósitos minerales o sustancias, así como cuantificar y evaluar las reservas económicamente aprovechables.

13 La explotación está destinada tanto a la preparación y desarrollo del área que comprende el depósito mineral, como a desprender y extraer los productos minerales o sustancias existentes, mientras que el beneficio o aprovechamiento es la recuperación u obtención de minerales o sustancias, y la elevación de la concentración y pureza de sus contenidos.

14 Cfr. García, Trinidad, op. cit. (n. 6), p. 57.

15 Los datos históricos de una Ley Minera datan desde la consumación de la independencia, ya que México heredó la legislación de la colonia, representadas por las Ordenanzas de minería que se siguieron aplicando y, también, las entidades federativas del país legislaron en esta materia, pero con sujeción a dichas Ordenanzas. Es en 1857 cuando el Congreso se encuentra ya facultado para establecer las bases de la legislación mercantil, incluyéndose la minería, y, en 1883, a través de una reforma constitucional, el Congreso quedó facultado para expedir códigos obligatorios de minería en toda la República, y en 1884 el Presidente de la República se encontraba facultado para expedir el Código de Minería, el cual fue sustituido por la Ley Minera de 14 de junio de 1892 , la cual vinculaba al Código de Comercio vigente en esa época. La Ley Minera fue abrogada por otra de fecha 25 de noviembre de 1909, estableciendo un sistema completo y especial de registro obligatorio de títulos y contratos mineros, con lo que se consolidó un Registro Público de Industrias Minerales. Posteriormente, surgió la Ley Minera de 1930 que, a su vez, sustituyó a la de 1926, afirmándose que la de 1930 implicó un golpe devastador para la pequeña minería al regresar a una política similar a la del Porfiriato. En 1961 se promulgó la Ley Reglamentaria del artículo 27 Constitucional en materia de explotación y aprovechamiento de recursos minerales, también conocida como Ley de Mexicanización de la Minería, cuyo propósito fue asegurar el control del Estado mexicano y el capital nacional sobre un sector que tradicionalmente había estado en manos de empresas extranjeras, con lo que se fortalecieron los empresarios mexicanos en este ramo. Más adelante se dio la Ley Minera, publicada en el Diario Oficial de la Federación, del 26 de junio de 1992, reformada el 26 de junio de 2006 y el Reglamento de la Ley Minera, publicado en el Diario Oficial de la Federación, de 15 de febrero de 1999, cfr. GARCíA, Trinidad, op. cit. (n. 6), pp. 58-60, y GONZÁLEZ-SÁNCHEZ, Francisco; CAmprubí, Antoni, "La pequeña minería en México", en: Boletín de la Sociedad Geológica Mexicana, vol. 62, N 1, 2010, http://boletinsgm.igeolcu.unam.mx/epoca04/6201/(5)Gonzalez-Sanchez.pdf [consultada el 27 de mayo de 2011].

16 El carbón mineral es la roca sedimentada de origen orgánico formada por diagénesis de materia vegetal, compuesta básicamente por carbono, hidrógeno y oxígeno, así como por pequeñas cantidades de azufre y nitrógeno con trazas de dióxido de carbono, metano y compuestos aceitosos; el gas asociado a los yacimientos de carbón mineral está formado principalmente por metano, asociado genéticamente al proceso de formación de carbón mineral, cuya ubicación se encuentra atrapada dentro de los mantos del mismo. Véase artículo 2, fracciones II y III, del Reglamento de la Ley Minera en Materia de Gas Asociado a los Yacimientos de Carbón Mineral, publicada en el Diario Oficial de la Federación, del 16 de diciembre de 2008. 
quiere decir que aquellas solo se otorgan si quien las solicita lo hace sobre un terreno libre; asimismo, hay que hacer notar que vale el principio de "primero en tiempo, primero en derecho" 17 , pues es al primer solicitante al que se le otorga la concesión si cumple con las condiciones y requisitos establecidos por la Ley y el Reglamento ${ }^{18}$. Al respecto, la concesión deberá hacer referencia siempre a las características que corresponden a su descripción física.

Las concesiones mineras tienen una duración de 50 años pudiendo ser renovables por otro período igual a solicitud de la parte interesada siempre que sus titulares no incurran en las causales de cancelación; mientras que las asignaciones tienen una duración de seis años improrrogables, al término de los cuales, acompañadas de la respectiva cancelación, el Servicio Geológico Mexicano procederá a declarar la libertad del terreno, la celebración de uno o más concursos para el otorgamiento de concesiones mineras, o la incorporación a reservas mineras del terreno amparado.

Entre los derechos ${ }^{19}$ que confiere una concesión minera destaca el obtener permiso de la Secretaría de Energía (SENER) para la recuperación y aprovechamiento de gas asociado a los yacimientos de carbón mineral. Dicho aprovechamiento puede ser para autoconsumo o para entregarlo a Petróleos Mexicanos (PEMEX), por ejemplo. Ahora bien, de tratarse de la exploración y explotación de carbón en todas sus variedades en terrenos amparados por asignación petrolera, las obras y trabajos que se realicen requerirán de la autorización de la SE previa consulta a la SENER para fijar las condiciones técnicas a que deban ajustarse.

Parte fundamental es el tema de las obligaciones a las que se someten los titulares de concesiones mineras, tanto por la exploración y explotación, así como por el beneficio de minerales que obtienen, en este caso, de los yacimientos de carbón mineral. Entre estas sobresalen la obligación de sujetarse a las disposiciones generales y a las normas oficiales mexicanas aplicables a la industria minero-metalúrgica en materia de seguridad en las minas y de equilibrio ecológico y protección al ambiente en donde, sin duda, en esta actividad existen grados elevados de riesgos de accidentes ${ }^{20}$ y enfermedades laborales, lo que representa para este tipo de empresas consecuencias negativas, por ello debiera ser su preocupación fundamental debido a los accidentes de trabajo, pago de indemnizaciones, afectación a las familias de los(as) trabajadores(as) y los costos indirectos para determinada empresa ${ }^{21}$; no retirar las obras permanentes de fortificación, los ademes (labor de apuntalamiento de los tiros y galerías), y demás instalaciones necesarias para la estabilidad y seguridad de las minas 22 ; permitir al personal comisionado por la SE la práctica de visitas de inspección; dar aviso

\footnotetext{
17 Salvo excepciones, véanse los artículos 12 BIS, 13, párrafos 2 y 3, y 13 BIS, párrafo 2, de la Ley Minera.

18 Cfr. Ley Minera, publicada en el Diario Oficial de la Federación, de 26 de junio de 1992, y el Reglamento de la Ley Minera, publicado en el Diario Oficial de la Federación, de 15 de febrero de 1999.

19 Véase artículo 19 de la Ley Minera.

20 Sobre este tema de accidentes, existe una obra muy completa si se desea profundizar: RAzous, Pablo, Curso de prevención de accidentes del trabajo, trad. Antonio Mayorga Briones, Gonzalo Paya Vilaplana y Tomás Sanchis Blasco. Madrid: Reus, S.A, 1933, pp. 10-633.

21 Cfr. Barona Peña, Rosa, "Cuánto vale la seguridad y salud de los trabajadores", en: Revista Emprendedores, al servicio de la mediana y pequeña empresa, $\mathrm{N}^{\circ} 116$, marzo-abril 2009, p. 22.

22 Estas son consideradas como accesiones de las minas, por tal motivo no pueden ser retiradas o destruidas (artículo 62 del Reglamento de la Ley Minera).
} 
a la SENER sobre el inicio y suspensión de las actividades, así como acumular, registrar y proporcionarle periódicamente información geológica relacionadas con la recuperación y aprovechamiento del gas asociado a los yacimientos de carbón mineral; avisar a la SENER sobre el descubrimiento de gas no asociado a los yacimientos de carbón mineral, como producto de las concesiones que amparan la exploración y explotación de yacimientos de carbón mineral, y entregar el gas asociado a los yacimientos de carbón mineral en el punto de conexión que indique PEMEX, en caso de que no se destine al autoconsumo.

Asimismo, la Ley Minera prevé la designación de un responsable ${ }^{23}$ (un ingeniero legalmente autorizado para ejercer) para el cumplimiento de las normas de seguridad en las minas, siempre y cuando, las obras y trabajos en las minas involucren a más de nueve trabajadores en el caso de las minas de carbón y más de 49 trabajadores en los demás casos. El responsable, quien será designado por el concesionario, además de verificar, principalmente, el cumplimiento de dichas normas, se encargará de que se tomen las medidas necesarias para prevenir accidentes y notificar de inmediato al titular de la concesión de explotación o a quien lleve a cabo esos trabajos aquellas medidas que no se hayan adoptado.

Otras obligaciones que sobrevienen, en este caso, por el aprovechamiento de los minerales o sustancias previstos por la ley de la materia, son dar aviso a la SE sobre el inicio de operaciones de beneficio; sujetarse a las disposiciones generales y a las normas oficiales mexicanas aplicables a la industria minero-metalúrgica en materia de seguridad y del equilibrio ecológico y protección al ambiente, así como permitir al personal comisionado por la SE la práctica de visitas de inspección en ejercicio de las facultades de verificación que le confiere la misma ley.

Por otra parte, las concesiones mineras podrán ser nulas, canceladas, o suspendidas y declarar insubsistentes los derechos que de estas se deriven de conformidad con lo establecido por la norma ${ }^{24}$. A ese respecto, y por razones de espacio, se hará mención únicamente a los supuestos más relevantes para el tema que se aborda. Así, tratándose de la cancelación de una concesión minera, esta podrá darse por: la terminación de su vigencia; el desistimiento debidamente formulado por su titular; la sustitución con motivo de la expedición de nuevos títulos; la comisión de alguna de las infracciones señaladas en el artículo 55 de la Ley, entre las que se encuentran no sujetar las obras y trabajos de exploración de carbón en todas sus variedades en terrenos amparados por asignaciones petroleras a las condiciones técnicas que fije la SE; realizar las obras y trabajos previstos por la Ley Minera sin las autorizaciones de la SE y de las autoridades que tengan a su cargo los bienes, zonas o áreas de las poblaciones, presas, canales, vías generales de comunicación y otras obras públicas donde se lleven a cabo; recuperar, almacenar, transportar y prestar servicio de entrega del gas asociado que derive de la recuperación y aprovechamiento de los yacimientos de carbón mineral, sin la autorización de la SENER; por recuperar, almacenar, transportar y prestar servicio de entrega del gas asociado a los yacimientos de carbón mineral, simulando sin realizar las actividades para las que le fue otorgada la concesión; enajenar el gas asociado que se derive de la

\footnotetext{
23 Cuando laboren en las obras y trabajos de explotación hasta 50 trabajadores, si el titular de la concesión, o quien lleve a cabo los mismos mediante contrato, es persona física podrá asumir las responsabilidades relativas al cumplimiento de las normas de seguridad en las minas, conforme al artículo 62 del Reglamento de la Ley Minera.

24 Véanse artículos 40 a 45 de la Ley Minera.
} 
recuperación y aprovechamiento de los yacimientos de carbón mineral; omitir información respecto al gas no asociado a los yacimientos de carbón mineral descubiertos en las fases de exploración y explotación de estos, o por perder la capacidad para ser titular de las concesiones, o por una resolución judicial.

La suspensión podrá ser declarada por la SE, previo derecho de audiencia, afectando el derecho para realizar las obras y trabajos previstos por la ley "cuando se ponga en peligro la vida o integridad física de los trabajadores o de los miembros de la comunidad", o bien, cuando se cause o pueda causarse daño a bienes de interés público, afectos a un servicio público o de propiedad privada. Si a consecuencia de la visita de inspección se revela peligro o daño inminente, entonces, la SE dispondrá de inmediato la suspensión provisional de las obras y trabajos, así como también la emisión de medidas de seguridad que se adoptarán dentro de un tiempo determinado pero, de no acatarse estas en el plazo fijado, procederá a la suspensión definitiva de tales obras y trabajos.

Las infracciones a la Ley Minera se castigarán, en algunos casos, con la cancelación de la concesión, a las que ya hicimos referencia y, en otros, será por multa. En este último caso, se procederá a sancionar con multas equivalentes de 10 a 2,000 días de salario mínimo general vigente en el Distrito Federal, cuando las infracciones consistan en extraer carbón mineral en cualquiera de sus variedades y el gas asociado a los yacimientos de este sin ser el titular de la concesión minera o de los derechos correspondientes; retirar o destruir las obras permanentes de fortificación, los ademes y demás instalaciones necesarias para la estabilidad y seguridad de las minas; impedir u obstaculizar las visitas de inspección que practique el personal comisionado por la SE; no concurrir por sí o a través de su representante, sin que medie causa justificada, a las visitas de inspección que practique la SE; no designar al ingeniero responsable del cumplimiento de las normas de seguridad en las minas o encomendarle actividades que le impidan el desarrollo de sus funciones propias; omitir la notificación que debiera hacer el ingeniero responsable (al concesionario de explotación o a quien lleve a cabo esos trabajos) sobre las medidas necesarias no adoptadas para prevenir accidentes "cuando pongan en peligro la vida o la integridad física de los trabajadores o de los miembros de la comunidad", así como por no tomar las medidas procedentes en caso de haberse recibido la notificación, y por no dar aviso a la SE sobre el inicio de operaciones de beneficio. El monto de la infracción será determinada por la SE, y es ejecutada por la Secretaría de Hacienda y Crédito Público (SHCP) con base a la gravedad de la infracción, los daños y perjuicios que haya causado, así como por los antecedentes, circunstancias personales y capacidad económica del infractor, previendo un mayor importe en caso de reincidencia. La aplicación de las multas se hará sin perjuicio de la responsabilidad penal que pudiera resultar.

Finalmente, la facultad que tiene la SE para verificar el cumplimiento de los deberes y obligaciones impuestas por la Ley Minera, así como para sancionar su inobservancia, tiene una vigencia de cinco años contados a partir de la fecha de incumplimiento o, en el caso de que sea continuo, a partir del día en que cese. Las resoluciones que emita esta, con motivo de la misma Ley y su Reglamento, podrán ser recurridas conforme a lo dispuesto en la Ley Federal de Procedimiento Administrativo. 


\section{DIFERENCIAS ENTRE MINAS Y POCITOS. EMPRESAS MINERAS DE CARBÓN: SU SUPERVISIÓN O INSPECCIÓN E INSTANCIAS PARA DENUNCIAR IRREGULARIDADES}

En esta materia de minas o de minería resalta expresamente una disposición constitucional, la fracción XV, con relación a la fracción XIII, del artículo 123 apartado A de la Constitución Política que señala "deben existir condiciones de seguridad e higiene" en las instalaciones que se ajusten a los ordenamientos legales en la materia, así como adopción de las medidas adecuadas para prevenir accidentes "con el propósito de garantizar la salud y vida de los trabajadores", entre los que se encuentran, por supuesto, los(as) mineros(as).

Asimismo, del artículo 512-B, con relación al 540, de la Ley Federal del Trabajo se desprende que, en cada entidad federativa, existirá una Comisión Consultiva Estatal de Seguridad e Higiene en el Trabajo, cuya finalidad es estudiar y proponer la adopción de todas aquellas medidas preventivas para abatir los riesgos en los centros de trabajo comprendidos en su jurisdicción. Son presididas por los gobernadores de los Estados, y en su integración participarán también representantes de las Secretaría del Trabajo y Previsión Social (STPS), la Secretaría de Salud (antes de Salubridad y Asistencia) y del IMSS, así como los que designen las organizaciones de trabajadores (sector obrero) y de patrones (sector patronal) a las que convoquen, conjuntamente, la STPS y el gobernador, y el representante de esta última Secretaría fungirá como Secretario de la Comisión Consultiva Estatal respectiva.

En este aspecto, se deben cumplir con las atribuciones que establecen los artículos 120, 121 y 122 del Reglamento Federal de Seguridad, Higiene y Medio Ambiente de Trabajo ${ }^{25}$. Bajo esta última normatividad, dicha Comisión Consultiva Estatal está obligada a estudiar y proponer a la Comisión Consultiva Nacional de Seguridad e Higiene en el Trabajo estudios en materia de seguridad, higiene y medio ambiente de trabajo, las "medidas preventivas de riesgos de trabajo y contribuir a su difusión", así como presentarle informes trimestrales respecto de los "programas de prevención de accidentes y enfermedades de trabajo" y de sus resultados.

Además del Reglamento Federal de Seguridad, Higiene y Medio Ambiente de Trabajo, existe otro reglamento, enfocado a la fiscalización de las normas laborales (conocida como inspección del trabajo ${ }^{26}$, la cual es toda una institución) ${ }^{27}$, como lo es el Reglamento General para la Inspección y Aplicación de Sanciones por Violaciones a la Legislación Laboral que, en sus artículos 8, fracción IV, y 14, fracción V, señala que las Delegaciones Federales del Trabajo (que dependen o forman parte de la estructura orgánica de la STPS) deben emprender las acciones necesarias para "garantizar la seguridad de los trabajadores al interior de una mina”, así como constatar que lo que se esté produciendo no dañe la salud de los(as)

\footnotetext{
25 Cfr. Diario Oficial de la Federación, de 21 de enero de 1997, http://www.diputados.gob.mx/LeyesBiblio/regla/n152.pdf [consultada el 25 de mayo de 2011].

26 Sobre la inspección del trabajo existe una obra muy completa y detallada sobre las responsabilidades técnicas, jurídicas, económicas, sociales y administrativas, así como medios de acción jurídicos de personal de inspección y de estructuras administrativas y, por último, los métodos y las reglas prácticas para llevar a cabo las visitas de inspección, para ello consúltese OFICina Internacional del Trabajo, La inspección del trabajo. Misión-Métodos. Ginebra, Suiza: OIT, 1973, pp. 7-210.

27 Cfr. MACíAS VÁZqueZ, María Carmen, "La inspección del trabajo: institución garante de los derechos laborales", en: Revista Latinoamericana de Derecho Social. La Inspección del Trabajo, No 6, enero-junio de 2008, pp. 32-35. México, Instituto de Investigaciones Jurídicas de la UNAM.
} 
trabajadores(as). Para ello, se deben recabar muestras de sustancias y materiales para ser examinados, y los inspectores tendrán la obligación de sugerir la adopción de las medidas de seguridad e higiene de aplicación inmediata en caso de peligro inminente, incluso proponer a las unidades administrativas competentes de la Secretaría la clausura total o parcial del centro de trabajo, sobre todo, "cuando se trata de empresas que representan mayor grado de peligrosidad" 28 , y las autoridades del trabajo podrán ordenar la práctica de visitas extraordinarias en cualquier tiempo, mismas que procederán cuando, entre otras, en una visita de inspección ordinaria, "tengan conocimiento de que existe inminente peligro para la integridad física o la salud de los(as) trabajadores(as)"29.

En ese mismo sentido, existen órganos administrativos especializados ubicados en la administración laboral (Dirección General de Inspección Federal del Trabajo) ${ }^{30}$ que realizan un control jurídico sobre la puesta en práctica de la norma laboral y que debe incidir en el desarrollo de esta última, pero hay que tener en cuenta que la infraestructura administrativa debe ser muy especializada (inspectores de trabajo) ${ }^{31}$, tema al que se ha enfocado la OIT.

En la actualidad, se busca que se redefina el papel de estos inspectores para adaptarlo a las nuevas tendencias de la política laboral y de empleo, en donde se tiene que enriquecer el catálogo de derechos fundamentales del (la) ciudadano(a) como trabajador(a), ya que su función principal es la prevención ${ }^{32}$, pero la propuesta de la OIT es que se amplíen sus funciones, porque han perdido actualidad, a pesar de que su papel debería ser relevante. Así, se considera que su función no solo es de asistencia técnica, sino de promoción de la revisión de las normas de trabajo vigentes en la protección del trabajo y de los(as) trabajadores(as); de identificar las posibles dificultades de la aplicación de la norma por su complejidad, y de generar diálogo social.

En este sentido, cuando la inspección en el trabajo no tiene medios para estar en todos los lugares y en todos los momentos no se asegura la eficacia en la adopción de medidas preventivas. La inspección de trabajo es fundamental en la preparación, administración, coordinación, control y evaluación de las políticas de empleo, laboral, social y de desarrollo de los recursos humanos ${ }^{33}$, y la misma es considerada como un instrumento del cumplimiento de los derechos fundamentales y de los derechos humanos en el trabajo sin dejar de

\footnotetext{
28 Cfr. Ibid., pp. 35 y 38.

29 Cfr. http://www.stps.gob.mx/02_sub_trabajo/01_dgaj/r_inspeccion.pdf [consultada el 25 de mayo de 2011].

30 Cfr. http://www.stps.gob.mx/bicentenario_plantilla/Elementos/organigrama.html [consultada el 29 de junio de 2011].

31 Para ampliar el tema sobre el número de Inspectores de las Delegaciones Federales del Trabajo, consúltese KURCZYN VILLALOBOS, Patricia, "La inspección: instrumento de cumplimiento de derechos humanos en el trabajo". En: FERRER MAC-GREGOR, Eduardo; Zaldífar Lelo De LaRREA, Arturo (coords.), La ciencia del Derecho Procesal Constitucional. Estudios a Héctor Fix-Zamudio en sus cincuenta años como investigador del derecho. Tomo XII. México: UNAM, Instituto Mexicano de Derecho Procesal Constitucional y Marcial Pons, 2008, pp. 635-640.

32 Este tema ha sido una preocupación recurrente en los legisladores, la han intentado consolidar al tratar de promover y vigilar el cumplimento de la normatividad en la materia, así como el Poder Ejecutivo federal y local. Para ello se crearon las Comisiones Mixtas de Seguridad e Higiene en el Trabajo, sin embargo, se advierten deficiencias, como la distancia real del cumplimiento de los programas anuales, por lo que se debe reforzar el diálogo en todas las Comisiones Mixtas de Seguridad e Higiene para prevenir accidentes, cfr. REYNOSO CASTILLO, Carlos, "Sobre las comisiones mixtas de seguridad e higiene", en: Alegatos, N 59, enero-abril 2005, pp. 88-90. México, Universidad Autónoma Metropolitana.

33 Cfr. Rodríguez-Piñero, Miguel, "El nuevo papel de la Inspección en el Trabajo”, en: Relaciones Laborales, Revista Crítica de Teoría Práctica, No 10, año XIX, mayo 2003, p. 12. España.
} 
ser un acto administrativo. Los inspectores deben cumplir con sus obligaciones determinadas en la normatividad respectiva y, si no lo hacen y se acreditan acciones $u$ omisiones, entonces deben ser sancionados de acuerdo con las leyes de responsabilidades administrativas y también en términos de la legislación penal. Su buen trabajo es determinante para prevenir violaciones a los derechos fundamentales y a los derechos humanos; por ejemplo, el derecho fundamental a la seguridad social, el derecho a la vida, a la salud ${ }^{34}$, y a su integridad física.

De forma histórica y luego comparativa, primero, en la Nueva España lo que caracterizaba a las minas dependía de muchas circunstancias, por ejemplo, la magnitud de las empresas que las poseían, si eran yacimientos recién descubiertos o minas antiguas, o por la profundidad donde se encontraban los depósitos, así como por las técnicas y métodos de extracción de la época ${ }^{35}$. Ahora en España lo que resalta es la inspección de trabajo y seguridad social, que consiste, a grandes rasgos, en realizar visitas in situ sin la necesidad de previo aviso; se da la comparecencia de los sujetos obligados con la documentación requerida en la oficina pública de la inspección; se tienen que comprobar los datos que obran en las instituciones de la Administración Pública; se abre un expediente administrativo cuando de su contenido se deducen elementos suficientes de comprobación de alguna irregularidad, de un acto u omisión; se tiene la obligación de facilitar información a la autoridad y a las instituciones financieras, y también se tiene la obligación de colaborar con la inspección del trabajo y, en su caso, se inician de oficio procedimientos sancionadores ${ }^{36}$.

Hoy en día, el ya referido Convenio 176 de la OIT sobre seguridad y salud en las minas, menciona que el término minas comprende los emplazamientos, subterráneos o de superficie, en los que se lleven a cabo, en particular, las actividades de exploración de minerales, excluidos el gas y el petróleo, que implique la alteración del suelo por medios mecánicos; la extracción de minerales, excluidos el gas y el petróleo; la preparación, incluidas la trituración, la molturación, la concentración o el lavado del material extraído, y todas las máquinas, equipos, accesorios, instalaciones, edificios y estructuras de ingeniería civil utilizados en relación con las actividades ${ }^{37}$.

En nuestro país existen empresas mineras de carbón que se pueden contar pero, además, existe un gran número de mineras pequeñas que, en su mayor parte, operan con las mínimas o casi nulas condiciones de seguridad e higiene. De ahí que existan minas y "pocitos" carboníferos. Estos últimos no son considerados como un desarrollo minero (es decir, una mina), sino que se trata, en lo individual, de un tiro vertical con una plancha que tiene pequeños túneles de donde se extrae el carbón, y estos solo cuentan con escasas medidas de seguridad. Tienen un diámetro de 1.20 metro, y los mineros descienden uno por uno en botes hasta una distancia de 60 metros para extraer el carbón, incluso utilizan los motores viejos de los automóviles para improvisar poleas que les ayuden a descender.

\footnotetext{
34 Cfr. Kurczyn Villalobos, Patricia, op. cit. (n. 31), pp. 615 y 617-618.

35 Cfr. Alatriste, Óscar, Desarrollo de la industria y la comunidad minera de Hidalgo del Parral durante la segunda mitad del siglo XVIII (1765-1810). México: UNAM, 1983, p. 33.

36 Cfr. DurÉndez SÁEZ, Ignacio, "La inspección de trabajo y el procedimiento sancionador", en: Anales de Derecho, № 21 , 2003, pp. 307-312. España, Universidad de Murcia.

37 Cfr. http://www.ilo.org/global/standards/subjects-covered-by-international-labour-standards/occupational-safety-andhealth/lang--es/index.htm [consultada el 27 de junio de 2011].
} 
Con relación a lo anterior, la minería en México tradicionalmente se ha considerado en tres tipos de empresas, aunque ahora también se afirma son cuatro, las cuales se definen de acuerdo a la cantidad de producción: 1. Empresas grandes; 2. Empresas medianas; 3. Empresas mineras pequeñas, y 4 . La minería artesanal ${ }^{38}$.

Sobre este apartado, la propiedad del sector minero mexicano está, en su gran mayoría, concentrada en manos del Grupo Industrial Minera México; Grupo Peñoles; Grupo Acerero del Norte (GAN), y el Grupo Villacero ${ }^{39}$. Respecto a la pequeña minería, la misma se encuentra ligada también a la cultura y economía de México, porque genera empleos, pese a que esto lo hace de manera formal e informal y, en ocasiones, puede rayar en lo rudimentario y lo artesanal; generalmente los mineros operan fuera de la legalidad, pero la ventaja es que para ellos existe un potencial económico, aunque sus perspectivas son de corta vida, no obstante han sobrevivido ${ }^{40}$.

En este sentido, se ha llegado a acreditar por inspectores federales del trabajo -caso mina Pasta de Conchos en febrero de 2006- que los particulares o empresas no contaban con diversas constancias relacionadas con programas de seguridad e higiene, entre estos con el Programa específico de seguridad para la prevención, protección y combate de incendios, que incluya la relación y tipo de equipo, su revisión, recarga y señalamientos; no se tenían registros de documentos que acreditaran que todos(as) los(as) trabajadores(as) participan en prácticas de simulacros de evacuación e incendio; se carecía de registros que acreditaran la realización, por lo menos una vez al año, de simulacros de evacuación de todo el personal a un lugar seguro, así como de incendios; no se disponía de un diagnóstico sobre las condiciones de seguridad e higiene que prevalecían; se encontró la ausencia de un programa de seguridad e higiene en el trabajo (general) que considere el cumplimiento de la normatividad en la materia; tampoco se contaba con un documento que acreditara que el patrón dio a conocer a los(as) trabajadores(as) el programa de seguridad e higiene; no tenían registros de revisión sobre el avance de cumplimiento al programa de seguridad e higiene en el trabajo; no existía un reporte por escrito de los resultados de la auditoría, al menos cada seis meses, del cumplimiento de dicho programa; se carecía de programas para la revisión, pruebas y mantenimiento de los sistemas estructurales de ventilación, instalaciones, equipos de prevención y protección contra incendios, derrumbes; no se mantuvo en buen estado el equipo eléctrico, neumático, la iluminación y los equipos de protección personal; no llevaban registro de antecedentes de alteraciones, reparaciones, modificaciones, condiciones de operación; faltaba el análisis de riesgos potenciales para las actividades de soldadura y corte que se desarrollaban en el centro de trabajo de acuerdo con lo establecido en el capítulo 7 de la NOM-027-STPS-2000, la cual se modificó posteriormente siendo la más reciente la NOM-027-STPS-2008, "Actividades de soldadura y corte - Condiciones de seguridad e higiene”, publicada en el Diario Oficial de la Federación, el 7 de noviembre de $2008^{41}$, y que

\footnotetext{
38 Cfr. http://www.stps.gob.mx/02_sub_trabajo/01_dgaj/r_inspeccion.pdf [consultada el 25 de mayo de 2011].

39 Cfr. ZAPATA, Francisco, "Las huelgas mineras de 2005-2006 del corporativismo a la autonomía sindical", en: Revista Internacional de Derecho y Ciencias Sociales, № 10, 2007, p. 104. México.

40 Cfr. GonZÁlez-SÁnCHeZ, Francisco; CAmprubí, Antoni, op. cit. (n. 15), p. 101.

41 Cfr. http://asinom.stps.gob.mx:8145/upload/noms/Nom-027.pdf [consultada el 17 de mayo de 2011].
} 
sirve para establecer las medidas preventivas para la protección del trabajador, de terceros y de las instalaciones del centro de trabajo; se carecía de estudios hidrogeológicos, para evaluar los riesgos de inundación, incluyendo procedimientos para su control, aprobados y firmados por el patrón y por los servicios preventivos de seguridad e higiene en el trabajo; existían fallas en los sistemas de extracción, operación segura del equipo, procedimientos de seguridad e higiene de acarreo de materiales que considere el equipo a utilizar, y sistemas de señales de operador, etc.

Además de todo lo anterior, como fue el caso de la mina Pasta de Conchos, al realizarse recorridos por las instalaciones de una mina se pudo detectar condiciones irregulares en materia de seguridad e higiene, relacionadas con reparaciones; iluminación o alumbrado; limpieza; controles eléctricos; dispositivos de seguridad; letreros alusivos al equipo y maquinaria que se energiza en las cajas eléctricas del interior de la mina; fugas de aceite y de gas, válvulas de seguridad faltantes; carencia de motores que accionen el extractor; falta de protección de seguridad en la cadena motriz, coples y terminal de banda para evitar riesgos mecánicos a los(as) trabajadores(as); falta de extintores del tipo $\mathrm{ABC}$ de polvo químico seco en el área del quebrador (es una maquinaria o instrumento, cuya función consiste en reducir el diámetro del mineral o bien pulverizarlo si es del caso); deficiente sistema de extracción de humos; vigas dañadas; no se hacía el polveo con polvo inerte en cielo, piso y tablas; no se mantenía libre de obstáculos el andador por donde transitaban los mineros; no se cambiaban las cajas de conexión eléctrica dañadas; los mineros no contaban con el equipo de protección adecuado para el desempeño de su labor, como guantes, cascos, linternas y otros aditamentos que evitan accidentes o daños a su salud.

De ahí, y derivado de la intervención de la Comisión Nacional de los Derechos Humanos $(\mathrm{CNDH})$ en el caso de la mina Pasta de Conchos, en donde el 19 de febrero de 2006, 65 mineros perdieron la vida al interior de esta, la CNDH solicitó un peritaje para determinar qué es lo que ocurrió el día de estos hechos, siendo el 6 de junio del mismo año que el presidente del Capítulo de Ingeniería, Geología, Minería y Metalúrgica del Colegio de ingenieros del Perú, Consejo Departamental de la Libertad, en Trujillo, Perú, y un ingeniero metalúrgico y superintendente de Planta de Procesos de la Compañía Minera Aruntani, Sac, en Trujillo, Perú ${ }^{42}$, emitieron una Opinión Técnica en donde para ellos:

"existen evidencias técnicas que permiten señalar la corresponsabilidad de la autoridad laboral por no hacer cumplir las normas y Reglamentos de seguridad, higiene y medio ambiente. Mismas que son competencia de la Secretaría del Trabajo y Previsión Social. De igual manera, hay evidencias técnicas que permiten acreditar la responsabilidad de la empresa Industrial Minera México, S. A. de C. V. (Unidad de Pasta de Conchos) por no cumplir a cabalidad con las normas y Reglamentos de seguridad, higiene y medio ambiente, así como también corresponsabilidad de los representantes de los trabajadores ante la Comisión de Seguridad e Higiene de la citada empresa, por permitir que los trabajos continúen en condiciones de inseguridad y al

\footnotetext{
42 Perú es un país que el 19 de junio de 2008 ratificó el Convenio 176 de la OIT sobre seguridad y salud en las minas, cfr. http://www.ilo.org/global/standards/subjects-covered-by-international-labour-standards/occupational-safety-and-health/langes/index.htm [consultada el 27 de junio de 2011].
} 
no acudir a las autoridades correspondientes para subsanar de inmediato las observaciones realizadas" 43 .

Lo ocurrido en la mina de Pasta de Conchos motivó la Recomendación de la CNDH número 26/2006, dirigida a la STPS ${ }^{44}$. Posteriormente, se presentaron deficiencias en la integración de la averiguación previa correspondiente, dado que el Ministerio Público (MP) de la Federación omitió pronunciarse de manera fundada y motivada sobre los planteamientos que le fueron formulados por los peritos oficiales de la propia institución para solicitar la intervención de expertos en materia de minería a efecto de contar con evidencias que permitieran determinar las causas de la explosión ocurrida ${ }^{45}$, lo que dio origen a otra Recomendación, la número $64 / 2008^{46}$, dirigida a la Procuraduría General de la República (PGR).

Por ello, en todos los casos de las minas de nuestro país es fundamental el trabajo que deben realizar las Delegaciones Federales del Trabajo de la STPS, quienes tienen que cumplir con lo establecido en el Programa de Inspección Federal y la normatividad de dicha Secretaría en materia de minas de carbón y, que por tratarse de un trabajo de alto riesgo, es su obligación realizar citatorios e inspecciones continuas, así como también, cuando se detecten irregularidades al interior de una mina, se deben señalar las medidas de seguridad e higiene que debe cumplir el particular o la empresa y, en su defecto, de no hacerlo estos últimos, la autoridad debe aplicar las medidas disciplinarias y sanciones que establece la ley. Esta labor la realizan mediante citatorios, órdenes de visita, actas de inspección periódica de condiciones generales de seguridad e higiene. Se elabora un emplazamiento a una determinada empresa o acta de entrega de emplazamiento en el que se le hace saber la existencia de condiciones de seguridad e higiene que no se ajustan a los ordenamientos legales en la materia y que impiden garantizar íntegramente la salud y la vida de los(as) trabajadores(as), y después es necesario realizar la visita correspondiente de inspección para comprobar que ya se realizaron las medidas de seguridad e higiene emplazadas.

Posteriormente, y por el incumplimiento de particulares o la empresa, es la Comisión Mixta de Seguridad e Higiene o la STPS quienes deberán hacer llegar a la SE un dictamen técnico en que se funde la solicitud de nulidad, suspensión o insubsistencia de los derechos de una concesión minera, conforme a lo señalado en el artículo 45 de la Ley Minera y, ante ello, la SE puede señalar las razones por las cuales sí o no procede a sancionar. Sin embargo, la deficiencia que existe, entre tantas otras, es que la autoridad no cuenta con un buen número de inspectores federales encargados de realizar visitas. Así, cuando hayan irregularidades en la actuación de servidores públicos locales o federales en esta materia se puede acudir ante los Órganos Internos de Control (OIC) o Contralorías Internas en cada Institución, ya

\footnotetext{
43 A ese respecto, además de la Opinión Técnica del 6 de junio de 2006, existe el dictamen basado en el estudio realizado por el Panel Internacional de Expertos en Seguridad en Minas y las opiniones del Consejo Consultivo Minero denominado Foro Consultivo Científico y Tecnológico, A. C.; y el dictamen del Servicio Geológico, el 19 de diciembre de 2008.

44 Cfr. http://www.cndh.org.mx/recomen/recomend.htm y http://www.cndh.org.mx/recomen/2006/026.htm [consultadas el 6 de junio de 2011].

45 http://www.cndh.org.mx/recomen/2006/026.htm, [consultada el 6 y 27 de junio de 2011].

46 Cfr. http://www.cndh.org.mx/recomen/2008/064.pdf, [consultada el 16 de junio de 2011].
} 
sea federal o local; por ejemplo, y solo por citar como casos, puede tratarse de la SE, la Secretaría de Salud, la SENER, o la STPS.

¿Ante qué instancia(s) y mediante qué recurso(s) pueden acudir los trabajadores de estas para denunciar las irregularidades del lugar donde trabajan? ¿Qué pasa si en un tiempo razonable no ven resultados de sus demandas para laborar con las condiciones necesarias de seguridad e higiene? Según el artículo 18 del Reglamento Federal de Seguridad, Higiene y Medio Ambiente de Trabajo, en sus fracciones II y III, indica que los trabajadores designan un representante ante la comisión de seguridad de su centro de trabajo y es su obligación dar aviso inmediato al patrón y a la comisión de seguridad e higiene de la empresa ${ }^{47}$, sobre las condiciones o actos inseguros que observen y de los accidentes de trabajo que ocurran en el interior de dicho centro y colaborar en la investigación de los mismos. En este sentido, en muchos de los casos, además de existir corresponsabilidad de la autoridad laboral por no hacer cumplir las normas y reglamentos de seguridad, higiene y medio ambiente; o de una determinada empresa por no cumplir a cabalidad con las normas y reglamentos de seguridad, higiene y medio ambiente, también puede existir corresponsabilidad de los representantes de los trabajadores ante la Comisión de Seguridad e Higiene de la empresa, por permitir que los trabajos continúen en condiciones de inseguridad y al no acudir a las autoridades correspondientes para subsanar de inmediato las observaciones realizadas.

En materia de protección civil, el artículo 14 de la Ley General de Protección Civil prevé que la primera instancia de actuación operativa especializada en caso de emergencia corresponde a la autoridad municipal o delegacional y, en su caso, a la instancia estatal; sin embargo, y a pesar de la trascendencia de ciertos hechos, la Coordinación General de Protección Civil de la Secretaría de Gobernación es solo la instancia que coadyuva en términos de coordinación con las autoridades federales y del estado con la supervisión de la STPS, conforme al precepto legal antes invocado, porque la norma lo que hace prevalecer es el respeto a la soberanía y autonomía de la entidad federativa y del municipio, situación que nos parece debiera modificarse. En este sentido, solo está previsto que, en caso de emergencia, corresponde a la autoridad municipal o a la delegacional y, en su caso, a la instancia estatal su intervención.

También existe la Procuraduría Federal de la Defensa del Trabajo (PROFEDET) que, de acuerdo a la Ley Federal del Trabajo, es un órgano desconcentrado de la STPS, cuyas atribuciones son las de orientar, asesorar y representar a los(as) trabajadores(as), sus sindicatos o beneficiarios(as), cuando estos(as) así lo solicitan, en forma gratuita, sobre los derechos y obligaciones de las normas de trabajo, de previsión social, de seguridad social, acerca de los trámites, procedimientos y órganos competentes ante los cuales los trabajadores pueden

\footnotetext{
47 Sobre el tema del funcionamiento de una Comisión de Seguridad e Higiene, encontramos que se han publicado dos obras, un Manual y una Guía. El primero se refiere a las normas legales relacionadas con este tipo de Comisiones, su integración, los elementos del acta para constituirlas, su funcionamiento, las visitas mensuales, investigación de accidentes, la promoción de la seguridad e higiene, las juntas periódicas, los informes de los accidentes en el trabajo, las estadísticas y otras actividades de dichas Comisiones. La segunda obra, explica con sencillez las causas y modos de prevenir los accidentes, las responsabilidades que derivan sobre los trabajadores y patrones, y señala qué es lo que deberá contener un Plan General Trabajo, para profundizar consúltese AgUiRre Martínez. Eduardo, Manual de Seguridad e Higiene para empresas comerciales, industriales y de servicio. México: Trillas, 1985, pp. 1-102 y Gómez Álvarez, Salvador, Guía de Trabajo para las Comisiones de Seguridad e Higiene. México: Secretaría del Trabajo y Previsión Social, 1960, pp. 15-113.
} 
acudir para hacerlos valer, así como representarlos cuando estos(as) lo soliciten ante los órganos jurisdiccionales, administrativos y cualquier otra institución pública o privada, a efecto de ejercitar las acciones y recursos que corresponden en la vía ordinaria, especial, e, inclusive, el juicio de amparo, hasta su total terminación ${ }^{48}$. Por otra parte, las violaciones a los derechos de los mineros cometidas por las empresas y los sindicatos pueden ser denunciadas ante las Juntas de Conciliación y Arbitraje (fracción XX del artículo 123 constitucional, apartado "A") y el Tribunal Federal de Conciliación y Arbitraje ${ }^{49}$.

También se cuenta con la PGR ${ }^{50}$ y las Procuradurías Generales de Justicia en cada estado de nuestro país, así como en el Distrito Federal, para que de conformidad con el artículo 21 de la Constitución y a través del MP y las policías, se haga la investigación de los delitos.

Otros órganos que brindan protección y promueven los derechos de cualquier persona, entre estos, los mineros, son la CNDH y las Comisiones o Procuradurías de Derechos Humanos de las 32 entidades federativas del país. A ese respecto, con anterioridad, antes del 10 de junio de 2011, aun cuando el artículo 102, apartado B, de la Constitución excluía de la competencia de la CNDH y de las comisiones estatales el conocimiento de los asuntos laborales, no implicaba desconocer los derechos humanos en el trabajo. Así, las violaciones a derechos humanos cometidas por servidores públicos eran (y son con mayor razón a partir de la reforma constitucional de 2011) ${ }^{51}$ competencia de las comisiones de derechos humanos, por actos y omisiones de naturaleza administrativa como son el incumplimiento de las normas de seguridad e higiene ${ }^{52}$. Ante estas situaciones, por ejemplo, en el caso de la mina de Pasta de Conchos los(as) servidores(as) públicos(as) de la STPS, al contestar el informe que les requirió la CNDH señalaron que dicha Comisión no era competente para conocer de la queja de referencia en razón de que se trataba de un asunto de carácter laboral, en términos de lo establecido en el artículo 102, apartado B, párrafo tercero de la Constitución. Sin embargo, la CNDH les precisó que, para efectos de la Constitución, con relación a la Ley de la misma, el asunto versaba sobre actos y omisiones concretos de naturaleza administrativa, emanados de los servidores públicos adscritos a la STPS, como el procedimiento administrativo de inspección periódica de condiciones generales de seguridad e higiene, previsto en el artículo 162 del Reglamento Federal de Seguridad, Higiene y Medio Ambiente de Trabajo, y la función inspectiva, a cargo de la STPS en términos de lo que establece la Ley Federal del Trabajo, sus reglamentos y la Ley Federal de Procedimiento Administrativo, por lo que en ese sentido la CNDH sí fue competente para conocer este caso ${ }^{53}$.

Además, esta reforma constitucional señala que todo servidor público está obligado a responder las recomendaciones que les presenten estos organismos, que cuando no las

\footnotetext{
48 Cfr. http://profedet.stps.gob.mx:75/paginas/q_profedet.htm y http://profedet.stps.gob.mx:75/paginas/tu_mejor_opcion. htm [consultadas el 16 de junio de 2011].

49 Cfr. Kurczyn Villalobos, Patricia, op. cit. (n. 31), p. 632.

50 Cfr. http://www.pgr.gob.mx/Que\%20es\%20PGR/presentacion.asp, [consultada el 16 de junio de 2011].

51 Cfr. Diario Oficial de la Federación, de 10 de junio de 2011.

52 Cfr. Kurczyn Villalobos, Patricia, op. cit. (n. 31), pp. 631 y 634.

53 Cfr. http://www.cndh.org.mx/recomen/2006/026.htm, [consultada el 27 de junio de 2011].
} 
acepten o no sean cumplidas por las autoridades o servidores públicos, estos deberán fundar, motivar y hacer pública su negativa; asimismo, la Cámara de Senadores o en sus recesos la Comisión Permanente, o las legislaturas de las entidades federativas, según corresponda, podrán llamar, a solicitud de estos organismos, a las autoridades o servidores públicos responsables para que comparezcan y expliquen el motivo de su negativa. Con esta reforma sobresale que estos organismos serán competentes tratándose de asuntos laborales en toda la extensión de la palabra, con la prohibición de que se trate de un asunto jurisdiccional.

Por otra parte, aunque en la mayoría de estos casos los hechos ya fueron denunciados ante los OIC y los agentes del MP, durante la tramitación del expediente respectivo en la $\mathrm{CNDH}$ esta puede solicitar información en colaboración a dichas autoridades, para analizar si se está presuntamente ante nuevos hechos violatorios como son la posible irregular integración de la averiguación previa o la dilación de la misma.

Sobresale que a partir de la reforma constitucional de la misma fecha al artículo primero de la Constitución "todas las personas" gozarán de los derechos humanos reconocidos en esta Constitución " $y$ en los tratados internacionales de los que el Estado Mexicano" sea parte, así como de las garantías para su protección, cuyo ejercicio no podrá restringirse ni suspenderse, salvo en los casos y bajo las condiciones que la Constitución establece. Asimismo, que las normas relativas a los derechos humanos se interpretarán de conformidad con la Constitución y con los tratados internacionales de la materia "favoreciendo en todo tiempo a las personas la protección más amplia”. Y, sobre todo, que todas las autoridades, en el ámbito de sus competencias, tienen la obligación de "promover, respetar, proteger y garantizar los derechos humanos" de conformidad con los principios de universalidad, interdependencia, indivisibilidad y progresividad, y que "el Estado deberá prevenir, investigar, sancionar y reparar las violaciones a los derechos humanos, en los términos que establezca la ley" 54 .

En este sentido, el artículo $113^{55}$ constitucional ya establece, aunque no de manera expresa desde la reforma del 14 de junio de 2002, que la responsabilidad del Estado por los daños que con motivo de su actividad administrativa irregular cause en los bienes o derechos de los particulares, será objetiva y directa, y los particulares tendrán derecho a una indemnización conforme a las bases, límites y procedimientos que establezcan las leyes ${ }^{56}$. Por ello, la indemnización por responsabilidad patrimonial del Estado se tiene que solicitar ante el Tribunal Federal de Justicia Fiscal y Administrativa. De tal forma se observa que, por la vía jurisdiccional, es dicho tribunal el encargado de conocer los juicios que se promuevan ya sea por resoluciones definitivas, actos administrativos o procedimientos que nieguen la indemnización, así como porque su monto no satisfaga al reclamante; "pero también conocerá de aquellos que impongan la obligación de resarcir los daños y perjuicios pagados con motivo de la reclamación, en los términos de la Ley Federal de Responsabilidad Patrimonial

\footnotetext{
54 Sobre este punto, el artículo segundo transitorio de dicha reforma constitucional establece que la ley a que se refiere el tercer párrafo del artículo 1o. constitucional sobre reparación deberá ser expedida en un plazo máximo de un año contado a partir de la entrada en vigor del presente decreto, cfr. Diario Oficial de la Federación, de 10 de junio de 2011.

55 Dicho artículo señala "la responsabilidad del Estado por los daños que, con motivo de su actividad administrativa irregular, cause en los bienes o derechos de los particulares, será objetiva y directa. Los particulares tendrán derecho a una indemnización conforme a las bases, límites y procedimientos que establezcan las leyes".

56 Cfr. Diario Oficial de la Federación, de 14 de junio 2002.
} 
del Estado o de las Leyes administrativas federales" que contengan un régimen especial de responsabilidad patrimonial del Estado ${ }^{57}$.

En cuanto a la participación de las Organizaciones No Gubernamentales (ONG), tanto internacionales como nacionales, las acciones que han realizado, para la promoción y protección de los mineros han sido muy importantes. De ahí que estas tengan un papel protagónico en esta materia, ya que con su trabajo se han presentado grandes avances en cuanto a la defensa de casos específicos.

Finalmente, en el ámbito internacional existen fundamentalmente dos grandes sistemas de defensa de los derechos humanos. Uno trabaja bajo el amparo de la Organización de las Naciones Unidas (ONU) y cuenta con siete órganos encargados de la vigilancia de los principales tratados internacionales de derechos humanos. Mientras que el Sistema Interamericano de Protección de los Derechos Humanos ${ }^{58}$ cuenta principalmente con la Comisión Interamericana de Derechos Humanos y la Corte Interamericana de Derechos Humanos 59 .

\section{LAS MINAS DE CARBÓN Y SU PELIGROSIDAD: EVENTOS TRÁGICOS POR NEGLIGENCIAS}

Ha habido un significativo progreso en la tecnología de la industria, pero ello no obsta a que una de las profesiones más peligrosas del mundo siga siendo la minería de carbón. Lo deseable es convertir las condiciones de los trabajos subterráneos en lo más seguras que humanamente sea posible. Para ello, además de adoptar medidas de orden material para mejorar la seguridad de los medios empleados en la extracción de carbón, es necesario, por ejemplo, esforzarse en la educación de los propios mineros para que, en mayor medida, contribuyan a la seguridad general de las minas ${ }^{60}$. A continuación veremos algunos eventos trágicos por negligencias en nuestro país.

Es de resaltar que la minería subterránea, de todo tipo, está considerada como una actividad de alto riesgo debido a la existencia de gases que provienen del mineral, a que existen rocas, fallas, fracturas, explosivos, equipos y por la maquinaria utilizada, entre otros; también en este tipo de actividad existe disminución del oxígeno que es necesario para la respiración de la persona; existe humedad por los propios factores internos de la mina y presencia de agua. Por ello, es fundamental que en estas siempre deban prevalecer condiciones óptimas de seguridad e higiene, sobre todo, por la peligrosidad de este tipo de minas. Sin embargo, es de observarse que no todas las minas cumplen con todos los requisitos para

\footnotetext{
57 Véase artículo 14, fracción VIII, de la Ley Orgánica del Tribunal Federal de Justicia Fiscal y Administrativa (Diario Oficial de la Federación, de 6 de diciembre de 2007, y artículos 24 y 33 de la Ley Federal de Responsabilidad Patrimonial del Estado (Diario Oficial de la Federación, de 31 de diciembre de 2004).

58 Cfr. García Ramírez, Sergio, "Raíz, actualidad y perspectivas de la jurisdicción interamericana de derechos humanos", en: Cuestiones Constitucionales. Revista Mexicana de Derecho Constitucional, № 20, enero-junio, 2009, p. 151. México, Instituto de Investigaciones Jurídicas de la UNAM.

59 Cfr. Ibid., pp. 167-190.

60 Cfr. Oficina Internacional del Trabajo, "La seguridad en las minas", en: Revista Internacional del Trabajo, vol. LXV, No 6, junio de 1962, pp. 623-624. Ginebra, Suiza.
} 
operar pero, para ello, existen, como ya lo vimos con anterioridad, autoridades facultadas para supervisar que sí se cumplan con dichas condiciones.

En el Estado de Coahuila, entre 1902 y 1976 se produjeron 19 grandes explosiones de gas grisú, con un saldo de 814 muertes. En Real del Monte, en Pachuca, entre 1946 y 1955, se dieron 121 muertes por accidentes de trabajo. En 1969 hubo una explosión en las minas de Barroterán con 142 mineros muertos. En 1978 en San Luis Potosí se cayó un malacate y murieron 16 trabajadores. En 1988, a raíz de una explosión en una mina de Coahuila, fallecieron 38 mineros $^{61}$.

En el contexto actual, durante 2005-2006, después de varios años de coexistencia pacífica entre el sindicalismo y el gobierno federal, se dieron varias huelgas de trabajadores mineros; por ejemplo, en Lázaro Cárdenas, Michoacán en 2005, en donde la CNDH emitió la Recomendación número 37/2006, de 10 de septiembre de 2006, sobre el caso de los hechos de violencia suscitados, el 20 de abril de 2006, en Lázaro Cárdenas, Michoacán, dirigida a la Secretaría de Seguridad Pública Federal y al Gobierno del Estado de Michoacán ${ }^{62}$. También han ocurrido muertes aisladas por despidos en Nacozari, Sonora, en donde, por ejemplo, el señor Reynaldo Hernández preparaba un mitín para exigir su reinstalación y falleció ${ }^{33}$. Además, por estos sucesos sobrevinieron frecuentes cuestionamientos a Napoleón Gómez Urrutia, en ese entonces, dirigente nacional del Sindicato Nacional de Trabajadores Mineros, Metalúrgicos y Similares de la República Mexicana (SNTMMSRN), quien fue acusado del mal manejo de 55 millones de dólares ${ }^{64}$. Este hecho ocurrió durante la época del accidente de la mina de Pasta de Conchos en febrero de 2006, anterior a los hechos de Lázaro Cárdenas, Michoacán, que también motivó de una Recomendación de la $\mathrm{CNDH}$, la número 26/2006, sobre el caso de los trabajadores de la empresa Industrial Minera México, S.A. de C.V. (unidad Pasta de Conchos), y dirigida a la STPS, donde fallecieron 65 mineros ${ }^{65}$.

En este sentido, cuando ocurren accidentes en las minas, se presentan los llamados costos indirectos u ocultos para una determinada empresa que, en muchos de los casos, pueden ser superiores a los costos fijos o directos (prima de riesgos de trabajo, gastos médicos, multas y recargos, prestaciones especiales, entre otros), lo que significa tiempo perdido, reducción en la productividad, salarios pagados en tiempo extraordinario, pago de daños, indemnizaciones, pago de abogados, desprestigio, averiguaciones previas, clausuras, consecuencias psicológicas sobre un gran número de personas, el abandono del trabajador a dicho empleo, porque sienten que desempeñan funciones altamente peligrosas, se tienen también consecuencias económicas negativas tanto para las empresas como para el país ${ }^{66}$.

\footnotetext{
61 Cfr. Zapata, Francisco, op. cit. (n. 39), pp. 108-109.

62 Cfr. http://www.cndh.org.mx/recomen/recomend.htm y http://www.cndh.org.mx/recomen/2006/037.htm [consultadas el 6 de junio de 2011].

63 Cfr. Sánchez Castañeda, Alfredo; Rueda Rodríguez, Alma Elena, "De la OIT a los mineros mexicanos", en: Revista Latinoamericana de Derecho Social. La Inspección del Trabajo, Nº 6, enero-junio de 2008, pp. 238-240. México, Instituto de Investigaciones Jurídicas de la UNAM.

64 Cfr. Ibid., pp. 239-240.

65 Cfr. http://www.cndh.org.mx/recomen/recomend.htm y http://www.cndh.org.mx/recomen/2006/026.htm [consultadas el 6 de junio de 2011].

66 Cfr. Barona Peña, Rosa, op. cit. (n. 21), pp. 22, 23 y 25.
} 
Asimismo, en ese preciso año de 2006, se dieron movimientos en las minas La Caridad (Nacozari de García, Sonora), y San Marín (Sombrerete, Zacatecas), entre otros sucesos, con la problemática de desarrollarse en zonas de aislamiento geográfico de las minas, así como los vínculos de los sindicatos con los partidos políticos, situaciones que con anterioridad ocurrieron en 1973, 1977 y en 1988 (al igual que en otros países: Bolivia, en 1987 y Perú, en 1970), por eso aumentaron la complejidad de las relaciones sociales en las minas y su peligrosidad.

Nuestra historia nos muestra que parece seguir ocurriendo lo mismo que en las primeras minas de México (Zacatecas, Guanajuato e Hidalgo). Por ejemplo, en la mina de Real del Monte en Pachuca se dio una explotación hace más de 300 años. A pesar de ello, en el siglo XIX surgieron otras minas, y en el XX la minería dejó de ser algo estratégico. A mediados de los años 50 se dio un prolongado conflicto de los mineros del carbón que culminó con la Caravana del Hambre ${ }^{67}$, y en el contexto actual, durante 2005-2006, se dan accidentes en las minas de nuestro país. Años más tarde, el 6 de agosto de 2009, dos personas perdieron la vida en el interior de la mina Lulú, en el municipio de Escobedo, Coahuila, lo que dio origen a la Recomendación de la CNDH número 12/2011, de 29 de marzo de $2011^{68}$. Mientras que una persona perdió la vida el 11 de septiembre del mismo año en el interior de la mina Ferber ${ }^{69}$, en el municipio de San Juan de Sabinas, Coahuila, dando como resultado la Recomendación de la CNDH número 85/201070.

Recientemente, en las instalaciones de Beneficios Internacionales del Norte S.A. de C.V. (Binsa), el 3 de mayo de 2011 murieron 14 mineros en el pozo 3 debido a una explosión, por lo que fueron clausuradas sus instalaciones en Sabinas, Coahuila. En este accidente también un menor de 15 años de edad resultó lesionado con quemaduras graves y la pérdida de un brazo ${ }^{71}$. Así nos percatamos que en la región carbonífera de Coahuila es común que sucedan accidentes acompañados de irregularidades administrativas y negligencias en donde existe corresponsabilidad de todas las partes ${ }^{72}$.

\footnotetext{
67 Cfr. ZAPATA, Francisco, op. cit., (n. 39), pp. 99, y 100-103.

68 Cfr. http://www.cndh.org.mx/recomen/2011/012.pdf [consultada el 17 de junio de 2011].

69 Sobre este caso, Carlos Rodríguez Rivera, integrante de la Organización Familia Pasta de Conchos, denunció ante la OIT que en México prevalece el trabajo de niños en las minas, por ejemplo, en el caso Ferber, cuando la mina fue inspeccionada en 2009 varios menores de edad trabajaron en la mina tres años antes de ser registrados para recibir seguridad social, a los 19 años, cfr. http://www.jornada.unam.mx/ultimas/2011/06/13/9540831-prevalece-trabajo-de-ninos-en-minas-mexicanas-denuncia-ante-oit [consultada el 13 de junio de 2011].

70 Recomendación No 85/2010, cfr. http://www.cndh.org.mx/recomen/2010/085.pdf [consultada el 16 de junio de 2011].

71 También en este caso, Carlos Rodríguez Rivera, integrante de la Organización Familia Pasta de Conchos, denunció ante la OIT que en México prevalece el trabajo de niños en las minas para "bajar costos de producción”, dijo que en los llamados "pocitos" de las minas de carbón los niños y jóvenes que no han alcanzado la estatura adulta resultan muy útiles, porque se les facilita trasladarse por los estrechos espacios, y por la forma como están dispuestos los espacios, es fácil esconderlos cuando se presentan los inspectores de la STPS. Prueba de ello, añadió, es el caso de Jesús Fernando Lara, de 14 años, quien sobrevivió. El joven, quien apenas cumplió 15 años, ya no estudiaba para dedicarse al trabajo de minería en el que le pagaban 900 pesos a la semana, cfr. http://www.jornada.unam.mx/ultimas/2011/06/13/9540831-prevalece-trabajo-de-ninos-en-minas-mexicanasdenuncia-ante-oit [consultada el 13 de junio de 2011].

72 Cfr. http://www.eluniversal.com.mx [consultada el 20 y 25 de mayo de 2011]. A ese respecto, el 13 de junio de 2011, los candidatos del Partido Acción Nacional (PAN) y del Partido Revolucionario Institucional (PRI), para la gubernatura estatal, visitaron la zona carbonífera de Coahuila, cfr. http://www.eluniversal.com.mx [consultada el 13 de junio de 2011].
} 
Después de este accidente, entre los acuerdos de la llamada "Cumbre del Carbón" destacan que se trabajará en la diversificación económica de la región; los tres ámbitos de gobierno iniciarán de inmediato los operativos de verificación de empresas e instalaciones de extracción minera; se fortalecerá el cumplimiento de las leyes y los reglamentos, tanto en materia de minería como de seguridad y salud en el trabajo de extracción de carbón mineral; se destinarán 50 millones de pesos para 50 proyectos de inversión, un millón de pesos por cada uno, que serán destinados a las empresas y etiquetados para la compra de equipos de seguridad y salud, a fin de elevar el nivel de seguridad para los mineros en la región carbonífera, y se contratarán a las empresas que se dediquen a certificar la calidad de los procedimientos de las carboneras ${ }^{73}$.

Sin embargo, el 11 de junio de 2011, tres mineros fallecieron al introducirse sin el equipo necesario al interior de la mina denominada Santa Rita de Otáez, en Durango, donde inhalaron un gas llamado mex-amonio (nitrato de amonio), tratándose de un lugar "donde supuestamente ya no se labora desde hace años", pero el gas se encontraba acumulado en recovecos de la mina. Según los testimonios de este caso, dos personas se introdujeron sin el equipo necesario, al pasar 10 minutos, como no salían entró el supervisor y también falleció $^{74}$.

En los últimos años, como lo hemos visto, se han presentado casos trágicos debido a omisiones y negligencias tanto de los titulares de las concesiones de las minas de carbón, así como de las autoridades respectivas. A ese respecto, la mayoría de los casos y fallecimientos ocurrieron no en minas modernas, sino en los llamados "pocitos" de carbón o carboníferos, a causa de explosiones por gas metano e inundaciones y, dicha actividad, en muchas ocasiones, se realiza de manera ilegal ya que no cuentan con la documentación correspondiente ni para formalizar una concesión ni un permiso, lo que aumenta el grado de ilegalidad y de riesgo en el que trabajan los(as) mineros(as). Incluso, la Secretaría de Medio Ambiente y Recursos Naturales, respecto del último caso ocurrido en Sabinas, Coahuila, señaló que la empresa solo cuenta con la autorización de impacto ambiental regional, y que esta no le da el derecho para laborar; además que debió presentar un "aviso de inicio de obra", para comenzar las labores de verificación de parte de la Procuraduría Federal de Protección al Ambiente (PROFEPA) en materia de afectación ambiental de aire, agua o suelo en aplicación del marco normativo ambiental. Así, las instalaciones ya fueron clausuradas y las autoridades trabajan en cancelar la concesión y, en este caso, existe la coordinación de los tres ámbitos de gobierno para realizar operativos de verificación de empresas e instalaciones de extracción de minerales, ya que se considera que más del 50\% de estas trabajan con "alguna" irregularidad, por lo que señalan las autoridades que, en esos casos, se buscará que proceda la suspensión de labores, la clausura o incluso la cancelación de la concesión. Se dice que esta acción es para fortalecer el cumplimiento de las leyes y los reglamentos, tanto en materia de minería como de seguridad y salud en el trabajo de extracción de carbón mineral.

A pesar de las condiciones ínfimas tanto de seguridad como de higiene las personas siguen trabajando en esta actividad; esto tal vez se deba a que, por ejemplo, en Coahuila no

\footnotetext{
73 Cfr. http:///www.eluniversal.com.mx [consultada el 9 de mayo de 2011].

74 Cfr. http://www.eluniversal.com.mx/notas/772145.html [consultada el 12 de junio de 2011].
} 
existe diversificación económica de la región, toda vez que actualmente el $80 \%$ de la actividad económica depende de la producción carbonífera. La Comisión Federal de Electricidad (CFE) consume unos 10 millones de toneladas de carbón, que en promedio tienen un costo de 820 a 840 pesos por tonelada, de las que compra una tercera parte a esa región carbonífera. De acuerdo con datos del IMSS, en el estado de Coahuila hay un registro patronal de 29.036 empleadores, de ellos 242 son del ramo minero y mantienen registrados a 17.806 trabajadores. El nivel salarial promedio con que trabajan los carboneros registrados en el IMSS es 5.2 veces el salario mínimo al día, lo que representa un poco más de 250 pesos diarios en promedio.

\section{REFERENTES PARA MÉXICO EN EL ÁMBITO DEL DERECHO INTERNACIONAL}

Sobre los referentes distintos al de México, igual que como pasa en nuestro país, los estudios relacionados con las regiones mineras son escasos.

Por ejemplo, en Cuba se profundizó en el tema de la propiedad minera, la historia legislativa de la minería, y su regulación hasta 192075. En España, en 1933 se enfocaron a estudiar qué pasaba en los pozos de extracción y los pozos de ventilación, y a analizar las principales causas de accidentes producidos en pozos, por desprendimientos o por caídas de piedras. Existen otras que provienen de la circulación y maniobras, del empleo de explosivos, del grisú, la asfixia, las inundaciones y los causados por las máquinas y aparatos diversos, entre estos, cables eléctricos ${ }^{76}$. En Argentina, en 1943, se tuvo la idea de crear una Dirección General de Minas de la Provincia de Catamarca, en donde se consideró que la minería tenía insospechadas posibilidades en lo económico. Existió la preocupación de los salarios de los mineros, que se tratase de mineros serios para que la explotación del subsuelo fuese inteligente. Esta Dirección estaría regida por el Código de Minería, Leyes y Reglamentos Mineros, con personal integrado por un Director, un Jefe Topógrafo, un Secretario que estaría auxiliado por un Escribano Público, quien llevaría todos los libros en esta materia (recibos, solicitudes, cateos, exploraciones, el libro de poderes, el libro de contratos y el libro de minas vacantes) y, por supuesto, se consideró la existencia de los inspectores, señalándose todos los procedimientos para realizar estas actividades por parte de estos servidores públicos, así como las prohibiciones para los concesionarios ${ }^{77}$.

Durante esta época, se consideró que poco se había hecho respecto de los problemas económicos, sociales y técnicos de la industria minera a pesar de que ya se habían planteado en numerosas ocasiones medidas internacionales respecto a la explotación de minas. Es así

\footnotetext{
75 Cfr. Corral, José Isaac del, Derecho minero cubano. Compilación de todas las disposiciones de carácter legislativo y administrativo dictadas, desde los más remotos tiempos hasta la fecha, para regular la adquisición y explotación de la propiedad minera en Cuba, precedida de un estudio de las legislaciones vigentes sobre la materia en todos los demás países y de una reseña sobre los origenes y el desarrollo de la minería cubana. Tomo I. La Habana, Cuba: Sociedad Editorial Cuba Contemporánea, 1920, pp. 3-675.

76 Cfr. Razous, Pablo, op. cit. (n. 20), pp. 139-141.

77 Cfr. Acuña, Eduardo, "Legislación Nacional. Proyecto de la Ley de creación de la Dirección General de Minas de la Provincia de Catamarca”, en: Revista de ciencias jurídicas y sociales, año VIII (3era época), Nº 38, 1943, pp. 152-180. Argentina, Universidad Nacional del Litoral.
} 
que el papel de la Organización Internacional del Trabajo (OIT), desde esos años, es fundamental, ya que esta organización hizo resaltar la importancia de la industria minera en la economía mundial, el elevado número de trabajadores y la necesidad de mejorar las condiciones de vida y de trabajo. Por ello, en 1955 la OIT tuvo una reunión a la que asistieron empleadores y trabajadores, en donde los principales temas que se abordaron fueron: los problemas sociales, prevención de accidentes, fijación de salario, protección del salario y las relaciones de trabajo, enfocándose a las minas distintas de las de carbón ${ }^{78}$.

Por otra parte, en Francia, durante 1962, se abordó el tema de la legislación y doctrina franco-belga en torno a la clasificación de sustancias minerales ${ }^{79}$. En la India, también en 1962, se partió del interés por determinar el tipo y número diario de trabajadores mineros de los yacimientos carboníferos, emplazamiento y características geológicas de los mismos, también sobre el tema de la legislación e inspección, la organización y dirección de las minas, el empleo y la formación profesional, los métodos de trabajo, la ventilación y los problemas que entraña, los servicios de salvamento, las estadísticas de accidentes y el mejoramiento de la seguridad en las minas de carbón ${ }^{80}$. En Sudáfrica, en 1987, se interesaron por las minas, pero de oro, abordando la organización que debe existir en este tipo de minas, de términos técnicos, como los barrenos, manipulación de los explosivos, y los problemas administrativos y el régimen de responsabilidades, concluyendo que ello va en detrimento de las medidas de seguridad y, por consiguiente, trae consigo, una crisis de autoridad ${ }^{81}$.

En este sentido, y en la actualidad, en el contexto internacional se parte de la base que el tema salarial y las leyes relacionadas con mineros se encuentra influenciado por el excedente de fuerza de trabajo y presencia de sindicatos con poca capacidad de negociación. Los temas importantes, a la vista del sector académico, son los convenios colectivos, la salud e higiene y seguridad en el trabajo, las relaciones internacionales, entre otros.

De igual manera, las empresas minero-metalúrgicas son en general empresas transnacionales, y se basan en los bajos costos para acceder a los recursos naturales, por lo que existe baja inversión en tecnología, los niveles salariales se han mantenido en los mínimos establecidos por la ley, lo que origina el trabajo informal y el infantil. Lo que resalta es que no hay profesionalización también de la mano de obra, se contrata a malos trabajadores, mano de obra poco calificada, mal pagados y su formación es pobre, por lo que se ha sugerido la creación de Centros de Formación Profesional, pero los cursos de profesionalización son escasos. Además, es necesario recordar que existe la obligación patronal de capacitación y el adiestramiento para con sus trabajadores.

En el ámbito internacional, algunas empresas han establecido políticas de salud y seguridad en el trabajo como son las normas ISO. En lugar de apegarse a la norma para evitar

\footnotetext{
78 Cfr. Oficina Internacional del Trabajo, "Problemas sociales en las minas distintas de las de carbón”, en: Revista Internacional del Trabajo, vol. LVI, julio-diciembre de 1957, p. 612. Ginebra, Suiza.

79 Cfr. Abdelnur, Asis, "La clasificación de las sustancias minerales en el nuevo Código Minero Francés", en: Anales de la Facultad de Ciencias Jurídicas y Sociales de la Universidad de La Plata, tomo XXI, 1962, pp. 321-343. La Plata, Argentina.

80 Cfr. Organización Internacional del Trabajo, "La seguridad en las minas de la India", en: Revista Internacional del Trabajo, vol. LXVI, No 3, septiembre de 1962, pp. 295-306. Ginebra, Suiza.

81 Cfr. LEgER, J.P., "La seguridad y la organización del trabajo en las minas de oro sudafricanas: la autoridad en crisis", en: Revista Internacional del Trabajo, vol. 106, N 1, enero-marzo, 1987, PP. 99-112. Ginebra, Suiza.
} 
accidentes la tendencia es que la empresa, al estar en presencia de uno y para disminuir los efectos de una tragedia, se alía con el sindicato.

En general, las empresas no cumplen estrictamente los convenios laborales en materia de salud y seguridad en el trabajo; se trata también de trabajos ocasionales.

El Banco Mundial en 2005 recomendó a las empresas velar por la protección de los derechos de las personas que se encuentran inmersas en los procesos de las industrias extractivas $^{82}$. Las autoridades en esta materia, a pesar que están lejos de ser homogéneas en diversos países, todos coinciden en tener mecanismos de solución de conflictos como el de control y seguimiento de la aplicación de la normatividad laboral ${ }^{83}$. Aquí es importante citar que la relación laboral "impone deberes jurídicos públicos cuya inobservancia constituye una infracción sancionable a través de medidas indirectas... por medio de sanciones administrativas, medios indirectos de tutela de los intereses y derechos privados ${ }^{84 "}$. Se deben cumplir las normas por encima de la voluntad de las partes, incluido el trabajador, entendido como el derecho protector del trabajo 85 .

En este sentido, las directrices relativas al sistema de gestión de la seguridad y la salud laborables emitidas por la OIT, consideran indispensable que las empresas empleen todos los recursos de infraestructura a su alcance para proporcionar a los(as) trabajadores(as) un ambiente de trabajo en donde la seguridad sea un compromiso compartido entre la empresa y la comunidad, haciéndose necesario que el gobierno, empresas y trabajadores unan sus esfuerzos en torno a un trabajo seguro, representando un factor positivo para la productividad y para el desarrollo económico de una Nación ${ }^{86}$.

El 5 de agosto de 2010, en Santiago, Chile, 33 mineros quedaron atrapados tras un derrumbe ocurrido al interior de la mina de San José, dedicada a la extracción de oro y cobre, mina que no debería estar en operaciones debido a una serie de accidentes ocurridos en el pasado. Después de 17 días y a 700 metros de profundidad los mineros dieron señales de vida, con lo que se iniciaron las labores de rescate, y con ese intento se originaron nuevos derrumbes en el interior del yacimiento. Se dio el rescate, gracias a una perforadora que logró llegar hasta los 688 metros, cerca del refugio, y luego de algunas horas los mineros hicieron subir un papel que señalaba "estamos bien en el refugio los 33 " 87 .

En Colombia durante 2010 se registraron 84 emergencias en minas, las cuales causaron la muerte de 173 trabajadores, 73 de ellos en un solo caso: una explosión en un yacimiento de carbón de la población de Amagá, en Antioquia (noroeste). Asimismo, el 26 de enero de 2011 una explosión de gas mató a 21 mineros en un yacimiento de carbón de Sardinata, localidad del departamento del norte de Santander (noreste), en la frontera con Venezuela. Uno más el 17 de mayo del mismo año, donde ocho mineros quedaron atrapa-

\footnotetext{
82 Cfr. PONT VIDAL, Joseph, "Trabajo y relaciones laborales en los enclaves minero-metalúrgicos de la Amazona oriental”, en: Revista Europea de Estudios Latinoamericanos y del Caribe, No 84, abril de 2008, pp. 38-39, 42-43, 45-47, y 54-56. Ámsterdam, Países Bajos.

83 Cfr. RodrígueZ-Piñero, Miguel, op. cit. (n. 33), pp. 1-2.

84 Ibid., p. 2.

85 Cfr. Ibid.

86 Cfr. Barona PeÑa, Rosa, op. cit. (n. 21), p. 25.

87 Cfr. http://www.perfil.com/contenidos/2010/08/22/noticia_0020.html [consultada el 24 de junio de 2011].
} 
dos por un derrumbe en una mina de carbón denominada Loma Gorda, situada en la vereda Los Limones, una zona rural cercana a Cali, la capital del Valle del Cauca, en el suroeste de Colombia, los cuales estaban con vida y los rescataron. En este caso sobresale que los mineros contaban con experiencia y que estaban atrapados solo a unos 90 metros de profundidad, por lo que fue fácil suministrarles oxígeno, además se trató de una mina que opera de forma legal y que varios obreros e ingenieros trabajaron en las labores de apuntalamiento para proceder al rescate ${ }^{88}$.

En el ámbito internacional, muchos de los anteriores países (Argentina, Chile, Colombia, Cuba, Francia, India y México) no han ratificado el Convenio 176 de la OIT sobre seguridad y salud en las minas, que entró en vigor en 1998, y que fue adoptado el 22 de junio de 1995, mientras que ya lo han hecho Albania, Alemania, Armenia, Austria, Bosnia y Herzegovina, Botswana, Brasil, Eslovaquia, España, Estados Unidos, Filipinas, Finlandia, Irlanda, Líbano, Luxemburgo, Noruega, Perú, Polonia, Portugal, República Checa, Sudáfrica, Suecia, Zambia y Zimbabwe.

Este tratado internacional toma en cuenta a los Convenios y Recomendaciones internacionales del trabajo pertinentes ${ }^{89}$. Para este Convenio su finalidad es prevenir todo accidente mortal, lesión o menoscabo de la salud de los trabajadores o de la población, o perjuicio al medio ambiente que tenga su origen en las operaciones mineras. Resalta en su artículo 3 que, previa consulta con las organizaciones más representativas de empleadores (empresas) y de trabajadores, el país deberá formular, aplicar y revisar periódicamente una política nacional en materia de seguridad y salud en las minas, que deberán establecerse medidas en este sentido a través de la legislación nacional, la que se debe complementar con normas técnicas, directrices o repertorios de recomendaciones prácticas, u otros medios de aplicación conformes con la práctica nacional. También que la legislación nacional mencionada deberá designar a la autoridad competente encargada de vigilar y regular los diversos aspectos de la seguridad y la salud en las minas; que la inspección de las minas se realice por inspecto-

88 Cfr. http://www.eluniversal.com.mx/notas/766116.html [consultada el 17 de mayo de 2011]. A ese respecto, en Colombia, de acuerdo con los datos oficiales 1, si en el año 2000 las exportaciones mineras constituían el $38 \%$ del total de las exportaciones, en el año 2009 alcanzaron el 51\% y se calcula que en los próximos 10 años ascenderán al 57\%. Además, entre 2000 y 2009, la participación del sector minero en la inversión extranjera directa se incrementó en 22 puntos (del 21 al 43\%) y se calcula que entre 2008 y 2015 el sector podrá recibir una inversión extranjera de 62.000 millones de dólares. Esto no da una idea acerca de la importancia que han adquirido los productos mineros, por eso es que algunos manifiestan que el sector minero es ahora tan importante para Colombia como lo ha sido desde siempre para países mineros por excelencia como Australia, Chile y Perú, cfr. http://www.dejusticia.org/interna.php?id_tipo_publicacion=1\&id_publicacion=856 [consultada el 29 de junio de 2011].

89 Como son los siguientes: el Convenio sobre la abolición del trabajo forzoso de 1957; el Convenio y la Recomendación sobre la protección contra las radiaciones de 1960; el Convenio y la Recomendación sobre la protección de la maquinaria de 1963; el Convenio y la Recomendación sobre las prestaciones en caso de accidentes del trabajo y enfermedades profesionales de 1964; el Convenio y la Recomendación sobre la edad mínima (trabajo subterráneo) de 1965; el Convenio sobre el examen médico de los menores (trabajo subterráneo) de 1965; el Convenio y la Recomendación sobre el medio ambiente de trabajo (contaminación del aire, ruido y vibraciones) de 1977; el Convenio y la Recomendación sobre seguridad y salud de los trabajadores de 1981; el Convenio y la Recomendación sobre los servicios de salud en el trabajo de 1985; el Convenio y la Recomendación sobre el asbesto de 1986; el Convenio y la Recomendación sobre seguridad y salud en la construcción de 1988; el Convenio y la Recomendación sobre los productos químicos de 1990, y el Convenio y la Recomendación sobre la prevención de accidentes industriales mayores de 1993, cfr. http://www.ilo.org/global/standards/subjects-covered-by-international-labourstandards/occupational-safety-and-health/lang--es/index.htm [consultada el 27 de junio de 2011]. 
res designados por la autoridad competente; que se determinen los procedimientos para la notificación e investigación de los accidentes mortales o graves, los incidentes peligrosos y los desastres acaecidos en las minas; que se lleve a cabo la compilación y publicación de estadísticas sobre los accidentes, enfermedades profesionales y los incidentes peligrosos; que se debe plasmar la facultad de la autoridad competente para suspender o restringir, por motivos de seguridad y salud, las actividades mineras, en tanto no se hayan corregido las circunstancias causantes de la suspensión o la restricción, y que se establezcan procedimientos eficaces que garanticen el ejercicio de los derechos de los trabajadores y sus representantes a ser consultados y a participar en las medidas relativas a la seguridad y la salud en el lugar de trabajo. Asimismo, para este Convenio o tratado internacional la legislación nacional deberá disponer que la fabricación, el almacenamiento, el transporte y el uso de explosivos y detonadores en la mina se lleven a cabo por personal competente y autorizado, o bajo su supervisión directa; que se deberán especificar las exigencias en materia de salvamento en las minas, primeros auxilios y servicios médicos adecuados; plasmar la obligación de proporcionar y mantener en condiciones apropiadas respiradores de autosalvamento a quienes trabajan en minas subterráneas de carbón y, en caso necesario, en otras minas subterráneas; se deberán establecer las medidas de protección que garanticen la seguridad de las explotaciones mineras abandonadas, a fin de eliminar o reducir al mínimo los riesgos que presentan para la seguridad y la salud, y determinar los requisitos para el almacenamiento, el transporte y la eliminación, en condiciones de seguridad, de las sustancias peligrosas utilizadas en el proceso de producción. De igual forma, dicha legislación nacional deberá disponer que el empleador responsable (empresa) de la mina garantice se preparen planos apropiados de la explotación antes de iniciar las operaciones y cada vez que haya una modificación significativa y que estos se actualicen de manera periódica y se tengan a disposición en el lugar de trabajo, y que, además, deberá evaluar los riesgos y tratarlos en el siguiente orden de prioridad: eliminar los riesgos; controlar los riesgos en su fuente; reducir los riesgos al mínimo mediante medidas que incluyan la elaboración de métodos de trabajo seguros, y en tanto perdure la situación de riesgo, prever la utilización de equipos de protección personal, tomando en consideración lo que sea razonable, practicable y factible y lo que esté en consonancia con la práctica correcta y el ejercicio de la debida diligencia; asegurarse de que la mina se diseña, se construye y se dota de equipos eléctricos, mecánicos y de otra índole, incluido un sistema de comunicación, de tal manera que se garantice una explotación segura y un medio ambiente de trabajo salubre; asegurarse de que la mina se pone en servicio, se explota, se mantiene y se clausura de modo que los trabajadores puedan realizar las tareas encomendadas sin poner en peligro su seguridad y salud ni la de terceras personas; adoptar medidas para mantener la estabilidad del terreno en las áreas a las que las personas tengan acceso por razones de trabajo; establecer, siempre que sea posible, dos vías de salida desde cualquier lugar subterráneo de trabajo, cada una de ellas comunicada con una vía independiente de salida a la superficie; asegurar la vigilancia, la evaluación y la inspección periódica del medio ambiente de trabajo para identificar los diferentes riesgos a que puedan estar expuestos los trabajadores, y evaluar el grado de exposición a dichos riesgos; asegurar un sistema de ventilación adecuado en todas las explotaciones subterráneas a las que esté permitido el acceso; en las zonas expuestas a riesgos especiales, preparar y aplicar un plan de explotación y procedimientos que garan- 
ticen la seguridad del sistema de trabajo y la protección de los trabajadores; adoptar medidas y precauciones adecuadas a la índole de la explotación minera para prevenir, detectar y combatir el inicio y la propagación de incendios y explosiones, y garantizar la interrupción de las actividades y la evacuación de los trabajadores a un lugar seguro en caso de peligro grave para la seguridad y la salud de los mismos. Este Convenio detalla ampliamente y con firmeza las obligaciones de los empleadores (o empresas), los derechos de los trabajadores, las obligaciones de los representantes de seguridad y salud como, por ejemplo, en el caso de estos últimos recurrir a consejeros y expertos independientes, y que se deberá fomentar la cooperación entre los empleadores (empresas) y los trabajadores y sus representantes destinadas a promover la seguridad y la salud en las minas ${ }^{90}$.

\section{NECESIDADES EN EL SISTEMA DE JUSTICIA MEXICANO PARA FORTALECER O HACER VIABLE LA OPERACIÓN DE LAS MINAS BAJO CONDICIONES DE SEGURIDAD E HIGIENE}

Hoy en día es necesario reiterar que la STPS desde 2006, con el caso Pasta de Conchos, se obligó y comprometió a hacer una revisión de todas las Delegaciones Federales adscritas a esa dependencia, a efecto de detectar el rezago en la materia, con el propósito de que sea abatido, debiendo implementar las medidas necesarias con la finalidad de que hechos como los de Pasta de Conchos, en ningún otro caso se presentarán en las minas de nuestro país.

También es necesario reiterar que los Delegados Federales del Trabajo, en su carácter de Secretarios Técnicos, exhorten al presidente de la respectiva Comisión Consultiva Estatal de Seguridad e Higiene en el Trabajo, para que, de conformidad con los artículos 512-B de la Ley Federal del Trabajo y 8, fracción IV, inciso a) del "Acuerdo por el que se determina la circunscripción territorial de las delegaciones, subdelegaciones y oficinas federales del trabajo de la STPS, y se delegan facultades en sus titulares", realicen sus funciones en forma periódica, quienes con la participación de determinado gobierno estatal, la STPS, la Secretaría de Salud, del IMSS, así como dos representantes designados por cada uno de los sectores obrero y patronal cumplan con las atribuciones que establecen los artículos 121 y 122 del Reglamento Federal de Seguridad, Higiene y Medio Ambiente de Trabajo.

Se señala que, por los avances tecnológicos, la internacionalización de la economía, la adopción de nuevas maquinarias, etcétera, es necesario profesionalizar a los inspectores del trabajo, esto es, que amplíen sus conocimientos, ya que su función de control original se amplía ${ }^{91}$.

Asimismo, se reitera que se deben destinar recursos económicos, pero que sean etiquetados por la Cámara de Diputados del Congreso de la Unión, con el objetivo de garantizar la seguridad para los(as) mineros(as).

Para fortalecer o hacer viable la operación de las minas como una necesidad en el sistema de justicia mexicano, requerimos, entre otras, contar con Opiniones Técnicas sobre las

\footnotetext{
90 Cfr. http://www.ilo.org/global/standards/subjects-covered-by-international-labour-standards/occupational-safety-andhealth/lang--es/index.htm [consultada el 27 de junio de 2011].

91 Cfr. Macías VÁzQueZ, María Carmen, op. cit. (n. 27), p. 37.
} 
minas de carbón, elaboradas por ingenieros, especialistas en minería y metalúrgica extranjeros y/o nacionales, para preparar a inspectores Federales del Trabajo de la STPS y de la SE. Es necesario aumentar las visitas de inspección y, en el caso de que se detecten situaciones que pongan en peligro la vida o seguridad de los mineros, se proceda a la clausura provisional de las minas.

Se tiene el dato que 100 inspecciones se han realizado en los últimos cinco años a minas, pozos y tajos o bancos de tres o más metros de altura, y que se ha sancionado a los empresarios que violan la ley con un monto total de 16 millones 443 mil pesos; sin embargo, desde 2006 se detectó que el número de inspectores no es suficiente y que se tenía que aumentar. A ese respecto, de conformidad con las cifras ofrecidas por la STPS eran 218 inspectores federales del trabajo en ese año (equivalente al $0.50 \%$ del promedio internacional), ahora en 2011 son 376 las plazas para esta actividad (equivalente al $0.87 \%$ del promedio internacional $)^{92}$, lo cual demuestra que seguimos por debajo de la media internacional. Con relación a este punto, el secretario del Trabajo en una comparecencia de mayo de 2011 reconoció que México registra un déficit de $371 \%$ en el número de inspectores para centros de trabajo, sobre todo en aquellos relativos a las minas. Proporcionó el dato que más de 4,800 inspecciones se han realizado en este sexenio, es decir, 34\% más que en el mismo período de la pasada administración. Esas 376 plazas equivales a que por cada 100,000 trabajadores haya 0.87 inspectores, mientras que la OIT recomienda 4.1 Inspectores. Por ello, el secretario del Trabajo dijo que se necesitan 1,395 plazas más ${ }^{93}$, para hacer un total de 1,771 inspectores. Por otra parte, debe considerarse que los actuales 376 deben desempeñar su labor entre 827,550 centros de trabajo a nivel nacional. Además, deben verificar que no se realice este trabajo por menores de edad, ya que la minería es una de las actividades más riesgosas. Además de lo anterior, se debe verificar que no se realice este trabajo de mineros por menores de edad, ya que la minería es una de las actividades más riesgosas.

También que sea obligatorio el uso de "metanómetros", instrumentos indispensables en una mina de carbón, porque miden la cantidad de gas metano en el ambiente y alertan a tiempo una situación de riesgo. La Norma Oficial Mexicana sobre Seguridad e Higiene NOM-023-STPS-2003 establece, en su Apéndice N denominado "Minas Subterráneas de Carbón", letra N.2, que el contenido de metano en el ambiente de la mina no debe exceder de $1.5 \%$ en volumen.

Es conveniente realizar investigaciones exhaustivas, porque las empresas mineras se registran con otros nombres. Los actos en donde exista responsabilidad de servidores públicos no deben quedar impunes.

Las instituciones correspondientes tendrán que ver y analizar la viabilidad de la propuesta para la creación del Instituto Nacional sobre Condiciones Laborales, Seguridad y Salud de los Trabajadores, que se dio a conocer a finales de 2010, en donde se señala que dicho Instituto podría desempeñar sus facultades sin ninguna presión externa al tratarse de un órgano autónomo, independiente de los poderes Ejecutivo, Legislativo y Judicial, para

\footnotetext{
92 Cfr. http://www.stps.gob.mx/bp/secciones/sala_prensa/boletines/2011/mayo/imagenes/Inspeccio...pdf [consultada el 3 de agosto de 2011].

93 Cfr. http://www.vanguardia.com.mx/mexicoregistraundeficitde371eninspectoreslaboraleslozano-736031.html [consultada el 3 de agosto de 2011].
} 
proteger el trabajo, la salud, la integridad y la vida de los(as) trabajadores(as), ya que para los(as) autores(as) de dicha propuesta los(as) trabajadores(as) se encuentran en constante riesgo de sufrir accidentes laborales por el incumplimiento de la legislación de la materia, y en donde es necesario que con dicho Instituto se vinculen trabajadores, patrones o empleadores, personal de salud, investigadores, entre otros, para conocer oportunamente la situación y resolver la problemática de las condiciones laborales, de seguridad y salud de los trabajadores ${ }^{94}$.

\section{A MANERA DE CONCLUSIONES Y PROPUESTAS, EN EL CONTEXTO ACTUAL, ¿DE QUÉ MANERA SE PUEDE REFORMAR ESTA MATERIA Y QUE SE TRADUZCA EN BENEFICIOS PARA LOS MINEROS MEXICANOS?}

En todos los países se deben buscar mejores expectativas de la calidad de vida de la población ${ }^{95}$, y que se fortalezca el régimen internacional en esta materia ${ }^{96}$.

Uno de los factores primordiales es incrementar la cultura de la responsabilidad en el ámbito de las empresas (o empleadores) sobre el tema de la seguridad e higiene en el trabajo y que se capacite a los mineros en esta materia. Para ello, existen las normas técnicas que deben seguir en su actividad, pero no todos las tienen plasmadas de manera completa. Por lo que son necesarios más esfuerzos con el fin de evitar accidentes como los ocurridos en los años recientes, y también aumentar el número de inspectores pero capacitados, así como el equipo y recursos necesarios para realizar su trabajo, que sean personas responsables, honestas (no corruptas) ${ }^{97}$, en donde, por ejemplo, en el caso de Pasta de Conchos en México esas fueron una de las peores acciones y omisiones de estos que salió a la luz pública, entre estas, su falta de profesionalismo, de recursos y de honestidad, por no decir corrupción al eliminar de las actas observaciones que se debían cumplir y que, simplemente, en lugar de subsanarlas las borraron o desaparecieron de dichos documentos.

También es necesario que la autoridad competente integre debidamente el Directorio Nacional de Empresas, a fin de detectar con oportunidad las irregularidades y realizar las vistas de inspección a los centros de trabajo mineros y prevenir futuros siniestros en las empresas concesionarias de lotes mineros.

En esta materia, reiteradamente se considera urgente que se proporcionen a las Delegaciones Federales del Trabajo los recursos materiales, económicos y humanos suficientes, a fin de establecer las medidas necesarias de prevención de accidentes y enfermedades de trabajo, tendientes a lograr que las actividades realizadas en las empresas concesionarias de lotes mineros se lleven a cabo en condiciones de seguridad, higiene y medio ambiente adecuados para los trabajadores, y que se establezca un sistema de intercambio de información con la SE, a fin de detectar los riesgos de trabajo y siniestros ocurridos en los lotes mineros.

\footnotetext{
94 Cfr. Noriega Elío, Mariano; Franco EnríqueZ, Jesús Gabriel et. al., "Propuesta para la creación del Instituto Nacional sobre Condiciones Laborales, Seguridad y Salud de los Trabajadores”, en: El Cotidiano. Revista de la realidad mexicana actual, No 162, julio-agosto de 2010, pp. 23-30. México, Universidad Autónoma Metropolitana.

95 Cfr. Rodríguez-PiÑero, Miguel, op. cit. (n. 33), p. 12.

96 Cfr. PONT VIDAL, Joseph, op. cit. (n. 82), p. 56.

97 Cfr. Kurczyn Villalobos, Patricia, op. cit. (n. 31), pp. 621 y 622.
} 
Por otra parte, y como se trata de una corresponsabilidad, respecto a los mineros es necesario tener en cuenta que si realizan este tipo de trabajo comprometen tanto su capacidad, integridad física y su derecho a la salud, y aumenta el riesgo de accidentes, para ello es conveniente que, además de ser sometidos a una completa capacitación técnica también se les realicen exámenes médicos con el fin de determinar su actitud para el trabajo. En este sentido todo síntoma o lesión puede poner gravemente en peligro su integridad y la de los otros mineros. Dentro de las afecciones más constantes a los que se hallan expuestos se encuentra la neumoconiosis debida a la excesiva acumulación de polvo en los pulmones, incluso, esta enfermedad profesional es mucho mayor que la de los accidentes mortales de las minas, por lo que es necesario que se refuerce el derecho a la salud de los mineros. El objetivo debe ser la eliminación de los riesgos del polvo y la prevención de la neumoconiosis $^{98}$. Asimismo, las violaciones a sus derechos cometidas por las empresas y los sindicatos deben ser denunciadas por los propios mineros ante las autoridades competentes. También los mineros deben contar con el equipo de protección adecuado para el desempeño de su labor, como guantes, cascos, linternas y otros aditamentos que evitan accidentes o daños a su salud; y es necesario que se esfuercen en su educación para que, en mayor medida, contribuyan ellos mismos a la seguridad general de las minas.

De igual manera, las empresas mineras son corresponsables y por ello tienen que fortalecer su inversión en tecnología, aumentar los niveles salariales y no fomentar el trabajo informal y el infantil. Tienen la obligación de profesionalizar la mano de obra (para hacerla calificada), contratar a buenos trabajadores, por lo que es necesaria la creación de Centros de Formación Profesional, tomando en consideración también que es una obligación patronal brindar la capacitación y el adiestramiento hacia sus trabajadores. En el ámbito internacional, algunas empresas han establecido políticas de salud y seguridad en el trabajo como son las normas ISO. Las empresas deben velar por la protección de los derechos de las personas que se encuentran inmersas en los procesos de las industrias extractivas. Para las empresas, el no seguir los lineamientos del Convenio 176 de la OIT sobre Seguridad y Salud en las minas, representa consecuencias negativas (como el caso de México que no lo ha ratificado), por lo que debiera ser su preocupación fundamental que, su respectivo país lo ratifique. Así, con la ratificación de este Convenio se garantizaría los derechos de los trabajadores; se daría la prevención de todo accidente mortal, lesión o menoscabo de la salud de los trabajadores o de la población, o perjuicio al medio ambiente que tenga su origen en las operaciones mineras; cada país tendría que formular, aplicar y revisar periódicamente una política nacional en materia de seguridad y salud en las minas a través de la legislación nacional, pero con una serie de obligaciones que señala este Convenio para todas las partes (trabajadores, sindicatos, empresas e instituciones públicas facultadas en esta materia) y que especifica las exigencias en materia de salvamento en las minas, primeros auxilios y servicios médicos y las medidas de protección que garanticen la seguridad de las explotaciones mineras abandonadas, así como recurrir a consejeros y expertos independientes.

En nuestro caso, en cuanto a la materia de protección civil, como ya lo vimos de forma breve en líneas anteriores de este trabajo, es necesaria una revisión de este tema o la ela-

98 Cfr. Oficina Internacional del Trabajo, "Problemas... (n. 60), pp. 609-610. 
boración de un análisis profundo sobre la Ley General de Protección Civil, porque solo está previsto que la primera instancia de actuación operativa especializada en caso de emergencia corresponde a la autoridad municipal o a la delegacional y, en su caso, a la instancia estatal; sin embargo, y a pesar de la trascendencia de ciertos hechos, la Coordinación General de Protección Civil de la Secretaría de Gobernación debiera tener más facultades en esta materia. De ser el caso, para las labores de rescate siempre deben solicitar la intervención de expertos, nacionales e internacionales, en materia de minería. En este aspecto, ya ocurrido un accidente, es obligación del MP no tener deficiencias en la integración de una averiguación previa, el cual debe cumplir con los planteamientos que le son formulados por sus peritos oficiales y/o sus resultados y, si es necesario, solicitar la intervención de expertos en materia de minería a efecto de contar con evidencias que permitieran determinar las causas de determinado hecho.

Finalmente, se puede hacer mucho en esta materia, lo urgente es que la mayoría de los países ratifique el Convenio 176 de la Organización Internacional del Trabajo (OIT) sobre Seguridad y Salud en las minas.

\section{BIBLIOGRAFÍA}

ABDelnur, Asis. "La clasificación de las sustancias minerales en el nuevo Código Minero Francés", en: Anales de la Facultad de Ciencias Jurídicas y Sociales de la Universidad de La Plata, tomo XXI. La Plata, Argentina, 1962.

ACUÑA, Eduardo. "Legislación Nacional. Proyecto de la Ley de creación de la Dirección General de Minas de la Provincia de Catamarca”, en: Revista de ciencias jurídicas y sociales, año VIII (3era época), N 38, 1943. Argentina, Universidad Nacional del Litoral.

Aguirre Martínez. Eduardo. Manual de Seguridad e Higiene para empresas comerciales, industriales y de servicio. México: Trillas, 1985.

Alatriste, Óscar. Desarrollo de la industria y la comunidad minera de Hidalgo del Parral durante la segunda mitad del siglo XVIII (1765-1810). México: UNAM, 1983.

BARONA PEÑA, Rosa. "Cuánto vale la seguridad y salud de los trabajadores”, en: Revista Emprendedores, al servicio de la mediana y pequeña empresa, № 116, marzo-abril 2009. México, UNAM.

Corral, José Isaac del. Derecho minero cubano. Compilación de todas las disposiciones de carácter legislativo y administrativo dictadas, desde los más remotos tiempos hasta la fecha, para regular la adquisición y explotación de la propiedad minera en Cuba, precedida de un estudio de las legislaciones vigentes sobre la materia en todos los demás países y de una reseña sobre los orígenes y el desarrollo de la minería cubana. Tomo I. La Habana, Cuba: Sociedad Editorial Cuba Contemporánea, 1920.

Diario Oficial de la Federación, de 14 de junio 2002.

Diario Oficial de la Federación, de 6 de junio de 2011.

Diario Oficial de la Federación, de 10 de junio de 2011.

DURÉNDEZ SÁEZ, Ignacio. "La inspección de trabajo y el procedimiento sancionador", en: Anales de Derecho, $\mathrm{N}^{\circ}$ 21, 2003. España, Universidad de Murcia.

García, Trinidad. "Registro de Concesiones y otros Actos, en Materia de Minas, Petróleo y Aguas", en: PEMEX Lex. Revista Jurídica de Petróleos Mexicanos, N 51-52, septiembre-octubre de 1992.

GARCÍA RAMírez, Sergio. "Raíz, actualidad y perspectivas de la jurisdicción interamericana de derechos humanos”, en: Cuestiones Constitucionales. Revista Mexicana de Derecho Constitucional, $\mathrm{N}^{\circ}$ 20, enero-junio, 2009. México, Instituto de Investigaciones Jurídicas de la UNAM. 
Gómez Álvarez, Salvador. Guía de Trabajo para las Comisiones de Seguridad e Higiene. México: Secretaría del Trabajo y Previsión Social, 1960.

GonZÁleZ-SÁNCHEZ, Francisco y Antoni Camprubí. "La pequeña minería en México”, en: Boletín de la Sociedad Geológica Mexicana, vol. 62, N 1, 2010, http://boletinsgm.igeolcu.unam.mx/epoca04/6201/(5)Gonzalez-Sanchez.pdf [consultada el 27 de mayo de 2011].

http://gaceta.diputados.gob.mx/Gaceta/Proposiciones/61/gp61_P_alprimero.html [consultada el 21 de junio de 2011].

http://portaltransparencia.gob.mx/pot/dependencia/showDependencia.do?method=beginerredireccionado=trueઐ_idDependencia $=14100$ [consultada el 16 de junio de 2011].

http://profedet.stps.gob.mx:75/paginas/q_profedet.htm [consultada el 16 de junio de 2011].

http://profedet.stps.gob.mx:75/paginas/tu_mejor_opcion.htm [consultada el 16 de junio de 2011].

http://sitl.diputados.gob.mx/listado_de_comisiones.php?tct=1 [consultada el 16 de junio de 2011].

http://www.cndh.org.mx/recomen/recomend.htm [consultada el 6 de junio de 2011].

http://www.cndh.org.mx/recomen/2006/026.htm [consultada el 6 y 27 de junio de 2011].

http://www.cndh.org.mx/recomen/2006/037.htm [consultada el 6 de junio de 2011].

http://www.cndh.org.mx/recomen/2008/064.pdf [consultada el 16 de junio de 2011].

http://www.cndh.org.mx/recomen/2010/085.pdf [consultada el 16 de junio de 2011].

http://www.cndh.org.mx/recomen/2011/012.pdf [consultada el 17 de junio de 2011].

http://www.dejusticia.org/interna.php?id_tipo_publicacion=16id_publicacion=856 [consultada el 29 de junio de 2011].

http://www.diputados.gob.mx/servicios/datorele/LX_LEG/1\%20POS\%20II\%20ANO/04-oct-07/2.htm [consultada el 21 de junio de 2011].

http://www.economia-dgm.gob.mx/Default.htm [consultada el 29 de junio de 2011].

http://www.economia.gob.mx/swbles/economialp_cgm_A3_registropublicomineria [consultada el 29 de junio de 2011].

http://www.eluniversal.com.mx [consultada el 9 de mayo de 2011].

http://www.eluniversal.com.mx [consultada el 20 y 25 de mayo de 2011].

http://www.eluniversal.com.mx [consultada el 13 de junio de 2011].

http://www.eluniversal.com.mx/notas/766116.html [consultada el 17 de mayo de 2011].

http://www.eluniversal.com.mx/notas/772145.html [consultada el 12 de junio de 2011].

http://www.ilo.org/global/standards/subjects-covered-by-international-labour-standards/occupational-safety-andhealth/lang--es/index.htm [consultada el 27 de junio de 2011].

http://www.jornada.unam.mx/ultimas/2011/06/13/9540831-prevalece-trabajo-de-ninos-en-minas-mexicanas-denuncia-ante-oit [consultada el 13 de junio de 2011].

http://www.perfil.com/contenidos/2010/08/22/noticia_0020.html [consultada el 24 de junio de 2011].

http://www.pgr.gob.mx/Que\%20es\%20PGR/presentacion.asp [consultada el 16 de junio de 2011].

http://www.pot.gob.mx/FastPOT2/search.jsp?collection=Fracciones \& $10=$ numHits\& query=MINAS[consultada el 29 de junio de 2011].

http://www.senado.gob.mx/index.php?ver=intormn=41 [consultada el 16 de junio de 2011].

http://www.sgm.gob.mx/index.php [consultada el 29 de junio de 2011].

http://www.stps.gob.mx/bicentenario_plantilla/Elementos/organigrama.html [consultada el 29 de junio de 2011]. 
http://www.stps.gob.mx/bp/secciones/sala_prensa/boletines/2011/mayo/imagenes/Inspeccio...pdf [consultada el 3 de agosto de 2011]

http://www.stps.gob.mx/07_justicia_lab/01_jfcaljfcainternet/index.htm [consultada el 16 de junio de 2011].

http://www.tfca.gob.mx/ [consultada el 16 de junio de 2011].

http://www.vanguardia.com.mx/mexicoregistraundeficitde371eninspectoreslaboraleslozano-736031.html [consultada el 3 de agosto de 2011].

KurCZyn Villalobos, Patricia. "La inspección: instrumento de cumplimiento de derechos humanos en el trabajo”. En: Ferrer MAC-GREGOR, Eduardo; ZaLdíVAR LELO DE LARREA, Arturo (coords.). La ciencia del Derecho Procesal Constitucional. Estudios a Héctor Fix-Zamudio en sus cincuenta años como investigador del derecho. Tomo XII. México: UNAM, Instituto Mexicano de Derecho Procesal Constitucional y Marcial Pons, 2008.

LEGER, J.P. "La seguridad y la organización del trabajo en las minas de oro sudafricanas: la autoridad en crisis”, en: Revista Internacional del Trabajo, vol. 106, N 1, enero-marzo, 1987. Ginebra, Suiza.

Ley Federal de Responsabilidad Patrimonial del Estado, publicada en el Diario Oficial de la Federación el 31 de diciembre de 2004.

Ley Minera, publicada en el Diario Oficial de la Federación, del 26 de junio de 1992.

Ley Orgánica del Tribunal Federal de Justicia Fiscal y Administrativa, publicada en el Diario Oficial de la Federación el 6 de diciembre de 2007.

MACíAS VÁZQUeZ, María Carmen. "La inspección del trabajo: institución garante de los derechos laborales", en: Revista Latinoamericana de Derecho Social. La Inspección del Trabajo, № 6, enero-junio de 2008. México, Instituto de Investigaciones Jurídicas de la UNAM.

Noriega Elío, Mariano; Franco EnríQUeZ, Jesús Gabriel et. al. "Propuesta para la creación del Instituto Nacional sobre Condiciones Laborales, Seguridad y Salud de los Trabajadores”, en: El Cotidiano. Revista de la realidad mexicana actual, N 162, julio-agosto de 2010. México, Universidad Autónoma Metropolitana.

Norma Oficial Mexicana NOM-027-STPS-2008, Actividades de soldadura y corte-Condiciones de seguridad e higiene, publicada en el Diario Oficial de la Federación, de 7 de noviembre de 2008, http://asinom.stps.gob. mx:8145/upload/noms/Nom-027.pdf [consultada el 17 de mayo de 2011].

Oficina Internacional del Trabajo. La inspección del Trabajo. Misión-Métodos. Ginebra, Suiza: OIT, 1973.

Oficina InTERnACIONAL Del Trabajo. "La seguridad en las minas", en: Revista Internacional del Trabajo, vol. LXV, N 6, junio de 1962. Ginebra, Suiza.

Oficina Internacional del Trabajo. "Problemas sociales en las minas distintas de las de carbón”, en: Revista Internacional del Trabajo, vol. LVI, julio-diciembre de 1957. Ginebra, Suiza.

Organización InternaCiOnAL DEL Trabajo. "La seguridad en las minas de la India”, en: Revista Internacional del Trabajo, vol. LXVI, N³, septiembre de 1962. Ginebra, Suiza.

PONT VIDAL, Joseph. “Trabajo y relaciones laborales en los enclaves minero-metalúrgicos de la Amazona oriental”, en: Revista Europea de Estudios Latinoamericanos y del Caribe, № 84, abril de 2008. Ámsterdam, Países Bajos.

Razous, Pablo. Curso de prevención de accidentes del trabajo, trad. Antonio Mayorga Briones, Gonzalo Paya Vilaplana y Tomás Sanchis Blasco. Madrid: Reus, S.A, 1933.

Reglamento de la Ley Minera, publicado en el Diario Oficial de la Federación, del 15 de febrero de 1999.

Reglamento de la Ley Minera en Materia de Gas Asociado a los Yacimientos de Carbón Mineral, publicada en el Diario Oficial de la Federación, del 16 de diciembre de 2008.

Reglamento Federal de Seguridad, Higiene y Medio Ambiente de Trabajo, Diario Oficial de la Federación, del 21 de enero de 1997, http://www.diputados.gob.mx/LeyesBiblio/regla/n152.pdf [consultada el 25 de mayo de 2011]. 
Reglamento General para la Inspección y Aplicación de Sanciones por Violaciones a la Legislación Laboral, Secretaría del Trabajo y Previsión Social, http://www.stps.gob.mx/02_sub_trabajo/01_dgaj/r_inspeccion. pdf [consultada el 25 de mayo de 2011].

Reynoso Castillo, Carlos. "Sobre las comisiones mixtas de seguridad e higiene", en: Alegatos, N 59, eneroabril 2005. México, Universidad Autónoma Metropolitana.

RodríGUEZ-PIÑERO, Miguel. "El nuevo papel de la Inspección en el Trabajo", en: Relaciones Laborales, Revista Crítica de Teoría Práctica, N 10, año XIX, mayo 2003. España.

SÁNCHEZ CASTAÑEdA, Alfredo; RuedA Rodríguez, Alma Elena. "De la OIT a los mineros mexicanos", en: Revista Latinoamericana de Derecho Social. La Inspección del Trabajo, Nº 6, enero junio de 2008. México, Instituto de Investigaciones Jurídicas de la UNAM.

ZAPATA, Francisco, "Las huelgas mineras de 2005-2006 del corporativismo a la autonomía sindical", Revista Internacional de Derecho y Ciencias Sociales, México, número 10, 2007. 


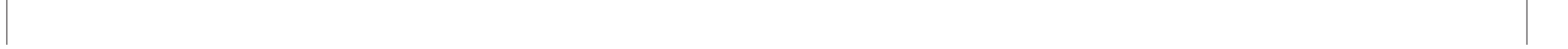

